\title{
The AP-1 transcription factors c-Jun and JunB are essential for CD8a conventional dendritic cell identity
}

\author{
Philipp Novoszel $^{1} \cdot$ Barbara Drobits $^{1} \cdot$ Martin Holcmann $^{1} \cdot$ Cristiano De Sa Fernandes $^{1} \cdot$ Roland Tschismarov $^{2}$. \\ Sophia Derdak ${ }^{3}$ Thomas Decker $\mathbb{1}^{2}{ }^{2}$ Erwin F. Wagner $\mathbb{1}^{4} \cdot$ Maria Sibilia $^{1}$
}

Received: 28 October 2020 / Revised: 17 February 2021 / Accepted: 24 February 2021 / Published online: 23 March 2021

(c) The Author(s) 2021. This article is published with open access

\begin{abstract}
Dendritic cell (DC) development is orchestrated by lineage-determining transcription factors (TFs). Although, members of the activator-protein-1 (AP-1) family, including Batf3, have been implicated in conventional (c)DC specification, the role of Jun proteins is poorly understood. Here, we identified c-Jun and JunB as essential for cDC1 fate specification and function. In mice, Jun proteins regulate extrinsic and intrinsic pathways, which control CD8 $\alpha \mathrm{cDC} 1$ diversification, whereas CD103 cDC1 development is unaffected. The loss of c-Jun and JunB in DC progenitors diminishes the CD8 $\alpha \mathrm{cDC} 1$ pool and thus confers resistance to Listeria monocytogenes infection. Their absence in CD8 $\alpha \mathrm{cDC} 1$ results in impaired TLR triggering and antigen cross-presentation. Both TFs are required for the maintenance of the CD8 $\alpha \mathrm{cDC} 1$ subset and suppression of $\mathrm{cDC} 2$ identity on a transcriptional and phenotypic level. Taken together, these results demonstrate the essential role of c-Jun and JunB in $\mathrm{CD} 8 \alpha \mathrm{cDC} 1$ diversification, function, and maintenance of their identity.
\end{abstract}

\section{Introduction}

Dendritic cells (DCs) are innate immune cells essential for the initiation of antigen-specific immune responses and maintenance of tolerance [1]. DCs originate from multipotent, hematopoietic precursors in the bone marrow (BM) and can be categorized into two distinct branches,

These authors contributed equally: Philipp Novoszel, Barbara Drobits

Edited by M. Bianchi

Supplementary information The online version contains supplementary material available at https://doi.org/10.1038/s41418021-00765-4.

Maria Sibilia

Maria.Sibilia@meduniwien.ac.at

1 Institute of Cancer Research, Department of Medicine I, Comprehensive Cancer Center, Medical University of Vienna, Vienna, Austria

2 Department of Microbiology, Immunobiology and Genetics, Max Perutz Labs, University of Vienna, Vienna, Austria

3 Core Facilities, Medical University of Vienna, Vienna, Austria

4 Department of Dermatology and Department of Laboratory Medicine, Medical University of Vienna, Vienna, Austria conventional (cDCs) and plasmacytoid DCs (pDCs), characterized by their unique transcriptional, functional, and cell surface phenotypes [2-4]. cDCs can be subgrouped in $\mathrm{cDC} 1$, specialized in cross-presentation and cDC2, critical for the induction of $T_{h} 2$ and $T_{h} 17$ immunity [5]. cDC1 can be identified by the expression of X-C motif chemokine receptor 1 (XCR1) and comprise a lymphoidresident $\mathrm{CD} 8 \alpha^{+}$and a non-lymphoid $\mathrm{CD} 103^{+}$population $[6,7]$. Over the last decade studies have shown that the differentiation into $\mathrm{CDC} 1$ is controlled by a network of specific, lineage-determining transcription factors (TF) $[8,9]$. TFs like the interferon regulatory factor 8 (IRF8), inhibitor of DNA binding 2 (ID2), and nuclear factor interleukin 3-regulated (NFIL3) are required for the diversification of the common DC progenitor (CDP) to cDC1 [10-12]. Furthermore, the basic leucine zipper transcription factor, ATF-like 3 (Batf3), a member of the dimeric activator protein-1 (AP-1) TF family, has been shown to maintain IRF8 expression in pre-cDCs, the direct clonogenic precursor to $\mathrm{CDCs}$, to safeguard $\mathrm{CDC} 1$ differentiation [13, 14].

AP-1 TFs comprise a group of homo- or heterodimers of basic leucine zipper proteins belonging to the Jun, Fos, MAF or ATF family with essential functions in development, cancer and immunity [15-17]. c-Jun and JunB are AP-1 family members with prominent roles in $\mathrm{T}$ cell 
development [18] and $\mathrm{T}_{\mathrm{h}} 17$ identity [19], respectively. Moreover, JunB inactivation in stem cells results in a myeloproliferative disorder characterized by increased numbers of granulocyte/macrophage progenitors (GMP) $[20,21]$. Functionally, c-Jun and JunB can be antagonistic but also compensatory, emphasizing that expression of some target genes is regulated equally by c-Jun and JunB. The inducible epidermal deletion of both c-Jun and JunB, for example, causes a psoriasis-like skin phenotype in adult mice, whereas single deletion results in no phenotype [22-25].

The interaction between Batf and Jun was originally considered to inhibit AP-1 transcriptional activity [26, 27]. However, a transcriptional complex between Jun/Batf and IRF4 or IRF8 enables binding to AP-1-IRF composite elements (AICEs), which is critical for the development of cDC1s [28] and the differentiation of $\mathrm{T}_{\mathrm{h}} 17$ cells [29, 30]. Although deletion of Batf3 in a genetically engineered mouse model (GEMM) demonstrated its role in CD8 $\alpha /$ CD103 development, the importance of Jun proteins, is poorly defined. In this study, we show that combined, immune cell-specific deletion of c-Jun and JunB leads to the selective loss of lymphoid CD8 $\alpha \mathrm{cDC} 1$, whereas nonlymphoid CD103 cDC1 differentiate normally. Importantly, c-Jun and JunB are required for cDC1-dependent immune responses, including activation upon TLR triggering and antigen cross-presentation. Mechanistically, our data reveal for the first time that c-Jun and JunB maintain cDC1 identity and suppress expression of $\mathrm{CDC} 2 \mathrm{TF}$ and surface markers.

\section{Methods}

\section{Animal studies}

$c-J u n^{\mathrm{f} / / \mathrm{fl}}$ and $J u n B^{\mathrm{f} / \mathrm{fl}}$ mice were crossed with $C D 11 c-\mathrm{Cre}$, $M x$-Cre or Tamoxifen (Tx) inducible $K 5$-Cre ${ }^{E R}$ mice, [31-34]. $M x$-Cre mice received one or two (indicated in Fig. legends) intraperitoneal injections of poly I: C (200 $\mu \mathrm{g}$; VWR) and $K 5$-Cre ${ }^{\mathrm{ER}}$ mice five consecutive injections of Tx (1 mg; Sigma Aldrich) for deletion. A 5\% cream formulation of Imiquimod (Aldara, Meda Pharma) was applied topically on shaved and waxed (Veet, Heidelberg, Germany) back skin for up to 7 days [35]. C57Bl/6 CD45.1, CD45.2 or CD45.1/CD45.2 were bred in house. Female and male mice of a mixed background $(129 \mathrm{~Sv} \times$ C57BL/6) and 8-16 weeks of age were used for studies. Mice were kept in the animal facility of the Medical University of Vienna in accordance with institutional policies and federal guidelines. All mice had access to food and water ad libitum.

\section{Flow cytometry}

Single cell suspensions of lymphoid organs and BM were prepared as follows. BM was flushed, spleen and lymph nodes were digested for $30 \mathrm{~min}\left(37^{\circ} \mathrm{C}\right)$ with Liberase $\mathrm{TM}^{\mathrm{TM}}$ $(50 \mu \mathrm{g} / \mathrm{mL}$; Roche) and DNAse I $(100 \mu \mathrm{g} / \mathrm{mL}$; Sigma Aldrich), filtered through a $70 \mu \mathrm{m}$ filter and washed. Red blood cells were lysed with ACK buffer. Single cell suspensions were blocked with anti-CD16/32 antibody (BioLegend) before addition of fluorescently labeled antibodies. Antibodies (see Supplementary Table 1) were diluted according to the manufacturer's recommendation and samples incubated on $4{ }^{\circ} \mathrm{C}$ for $30 \mathrm{~min}$. Absolute cell number was assessed with a CASY cell counter (Beckman Coulter) or by addition of 123 count eBeads (Thermo Fisher Scientific). Cells were acquired on a LSR Fortessa cell analyzer (BD Biosciences) and analyzed with FlowJo software (Treestar).

\section{Intracellular cytokine staining}

For intracellular staining of IL-12 p40 (C15.6; BioLegend) cells were stimulated with poly I: C $(1 \mu \mathrm{g} / \mathrm{mL}$; VWR) in the presence of Brefeldin A (BioLegend) for $5 \mathrm{~h}$. Surface markers were stained before fixation and permeabilization with the BD Cytofix/Cytoperm Kit (BD Biosciences). IRF4 (3E4; eBioscience) and IRF8 (V3GYWCH; eBioscience) were stained intracellular in spleen and lymph-node using the Foxp3/Transcription Factor Staining Buffer Set (eBioscience).

\section{Cell culture}

$\mathrm{BM}$ cells were isolated from femur/tibia and red blood cells were lysed. $3 \times 10^{6}$ cells $/ \mathrm{mL}$ were cultured in RPMI supplemented with $10 \%$ FCS, $1 \%$ Pen/Strep, sodium pyruvate, nonessential amino acids and $0.1 \% \quad \beta$ mercaptoethanol. Recombinant mFLT3L $(80 \mathrm{ng} / \mathrm{mL}$, Peprotech) was added to induce cDC and pDC differentiation. For $\mathrm{CD}_{103^{+}} \mathrm{cDC}$ in vitro differentiation $\mathrm{BM}$ cells were depleted of lineage-positive cells using the lineage cell depletion kit (Miltenyi Biotec). Enriched cells were cultured in complete medium supplemented with recombinant mFLT3L (80 ng/mL, Peprotech) and recombinant mGM-CSF ( $10 \mathrm{ng} / \mathrm{mL}$, Peprotech) for 12 days. On day 6 fresh culture media supplemented with recombinant mFLT3L and mGM-CSF was added.

\section{Generation of bone marrow chimeric mice}

BM chimeric mice were generated by intravenous (i.v.) injection of $\mathrm{CD} 3 \varepsilon / \mathrm{CD} 90.1 .-\mathrm{MACS}$-depleted $\mathrm{BM}$ cells 
$\left(4 \times 10^{6}\right)$ into lethally irradiated mice $(8.25-9 \mathrm{~Gy})$. For mixed BM chimeras, BM cells of two different donors (CD45.1/2 wild-type and CD45.2 c-Jun/JunB deficient) were mixed in a ratio 1:1 before injection. Experiments were performed after a reconstitution period of at least 8 weeks. Poly I: C was injected into chimeric mice twice, 5 days apart, and mice were analyzed 14 days after Cre induction.

\section{In vivo a-G-CSF antibody treatment}

Mice were treated with $50 \mu \mathrm{g}$ of $\alpha$-GCSF IgG (clone 67604, Sigma Aldrich), or matched isotype control (rat IgG, BioXCell) by intraperitoneal injection 2 and 4 days after poly I: C induced deletion of c-Jun/JunB in the $M x$-Cre mouse model.

\section{Listeria infection model}

An overnight culture of L. monocytogenes strain LO28 was re-cultured in BHI medium to late log phase, pelleted and diluted in PBS. The concentration of bacteria was quantified by optical density measurements at $600 \mathrm{~nm}$ and confirmed by plating serial dilutions on BHI agar plates and colony counting. $1 \times 10^{6} \mathrm{cfu}$ were injected into the peritoneum of 8- to 15-week-old mice. Animals were euthanized after 24 and $72 \mathrm{~h}$, spleens and livers were isolated, weighed and homogenized, and serial dilutions were plated on BHI agar plates. Colonies were counted after $\sim 30 \mathrm{~h}$ culture at $37^{\circ} \mathrm{C}$.

\section{In vitro cross-presentation}

c-Jun/JunB $\mathrm{cDC}^{\mathrm{FL}}$ were obtained by negative selection of $\mathrm{B} 220^{+} \mathrm{pDC}^{\mathrm{FL}}$ by MACS on day 7 of FLT3L-supplemented $\mathrm{BM}$ cultures. $\mathrm{cDC}^{\mathrm{FL}}$ were then loaded with Ovalbumin $(250 \mu \mathrm{g} / \mathrm{mL})$ or SIINFEKL $(20 \mu \mathrm{g} / \mathrm{mL})$ for $6 \mathrm{~h}$, washed and re-plated at $2 \times 10^{4}$ with CFSE labelled $(1 \mu \mathrm{M}, 10 \mathrm{~min})$ OT-I $\mathrm{T}$ cells in a 1:100 $\mathrm{cDC}^{\mathrm{FL}}$ to OT-I T cell ratio. OT I- T cells were enriched from lymphoid organs of OT-I mice by negative depletion of $\mathrm{B}\left(\mathrm{CD} 19^{+}, \mathrm{B} 220^{+}\right)$, NK $\left(\mathrm{NK} 1.1^{+}\right)$, DC $\left(\mathrm{CD} 11 \mathrm{c}^{+}\right)$and myeloid $\left(\mathrm{CD} 11 \mathrm{~b}^{+}\right)$cells. After 3 days of co-culture, proliferation of OT-I T cells was analyzed by CFSE dilution in TCR $\beta^{+} \mathrm{CD} 8 \alpha^{+}$cells.

\section{Quantitative PCR}

Total RNA was isolated with TRIzol reagent (Invitrogen) and cDNA synthesis was done with SuperScript IV Reverse Transcriptase (Thermo Fisher Scientific). Real-time PCR was performed with SYBR Green Master Mix (Applied Biosystems) on a CFX96 Touch System (BioRad).
Differential expression is shown as fold change and was calculated with the $\Delta \Delta \mathrm{Ct}$ method. Expression was normalized to the house keeping gene Tbp (TATA-binding protein). Primers used for quantitative PCR are listed in Supplementary Table 2.

\section{RNA-sequencing}

FLT3L-derived $\mathrm{cDC} 1^{\mathrm{FL}}\left(\mathrm{CD} 24^{+} \mathrm{CD} 11 \mathrm{c}^{+} \mathrm{B} 220^{-} \mathrm{CD} 115^{-}\right.$

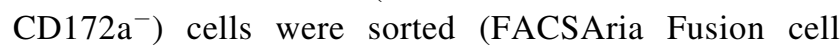
sorter; BD Biosciences) into TRIzol LS reagent (Invitrogen) and RNA was isolated with the miRNeasy Micro Cleanup Kit (Qiagen). Sequencing libraries were prepared using the NEBNext Poly (A) mRNA Magnetic Isolation Module and the NEBNext Ultra ${ }^{\mathrm{TM}}$ II Directional RNA Library Prep Kit for Illumina according to manufacturer's protocols (New England Biolabs). Libraries were QC-checked on a Bioanalyzer 2100 (Agilent) using a High Sensitivity DNA Kit for correct insert size and quantified using Qubit dsDNA HS Assay (Invitrogen). Pooled libraries were sequenced on a NextSeq500 (Illumina) in $2 \times 75$ bp paired-end sequencing mode. Reads in fastq format were aligned to the murine reference genome version mm10 (https://www.ensembl.org) with Gencode vM19 annotations (https://www.gencodegenes.org/) using STAR aligner [36] version 2.6.1a in 2-pass mode. Reads per gene were counted by STAR, and differential gene expression was calculated using DESeq2 [37] version 1.20.0. Principal component analysis (PCA) and Euclidean distance plots were generated using $\mathrm{R}$ functions prcomp and dist, respectively. GO term enrichment analysis was performed with GOrilla [38] using as an input selections of differentially expressed genes (DEGs) and all mouse Ensemble gene ids as a background. Gene set enrichment analysis (GSEA) was performed using GSEA [39] version 3.0 using as an input regularized logtransformed count data from DESeq2 and selected gene sets from MSigDB [40] version 6.2 as well as custom gene sets.

\section{Venn diagram}

To generate Venn diagrams we first made a list of probe sets derived from the published microarray data with the Transcriptome Analysis Software (Thermo Fisher Scientific). We then used the GSEA software (http://www. gsea-msigdb.org/gsea/index.jsp) to collapse the values of the probe sets to a single gene value by gene using the median probe mode. We considered only genes that were annotated on both, the microarray and RNA-Seq platform. We used the R function euler to generate a Venn diagram. 
a
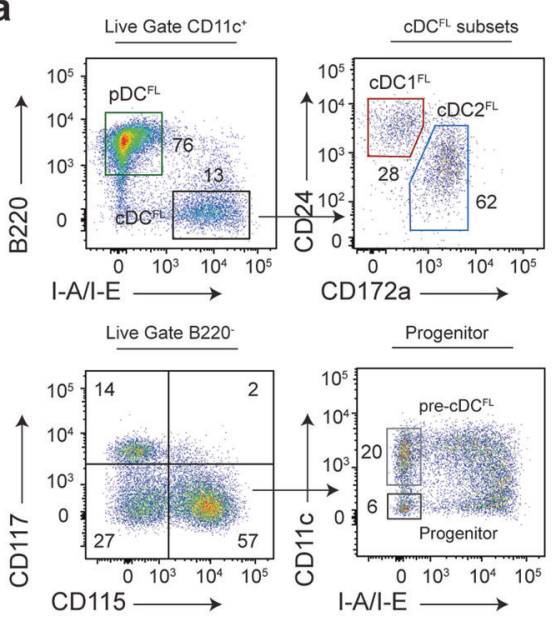

b

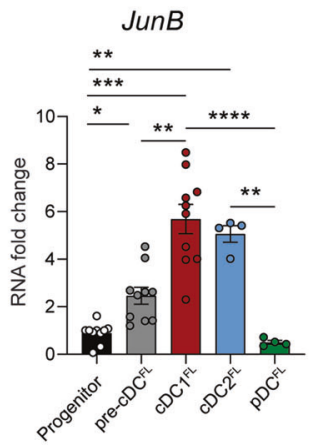

c-Jun/JunB $B^{\Delta \Delta} M x-C r e$
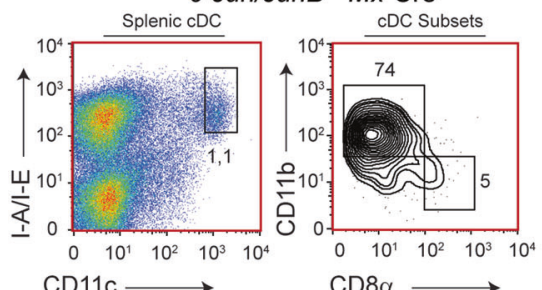

$\mathrm{CD} 11 \mathrm{c} \longrightarrow$

g
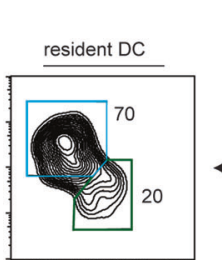

C-Jun/Jun $B^{\mathrm{f} / \mathrm{m}}$

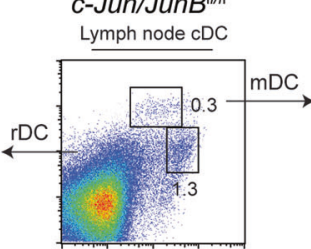

C-Jun/JunB ${ }^{N \Delta} M x-C r e$
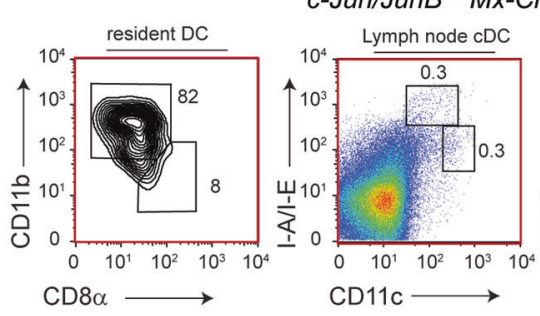

C

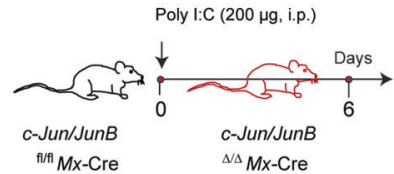

e
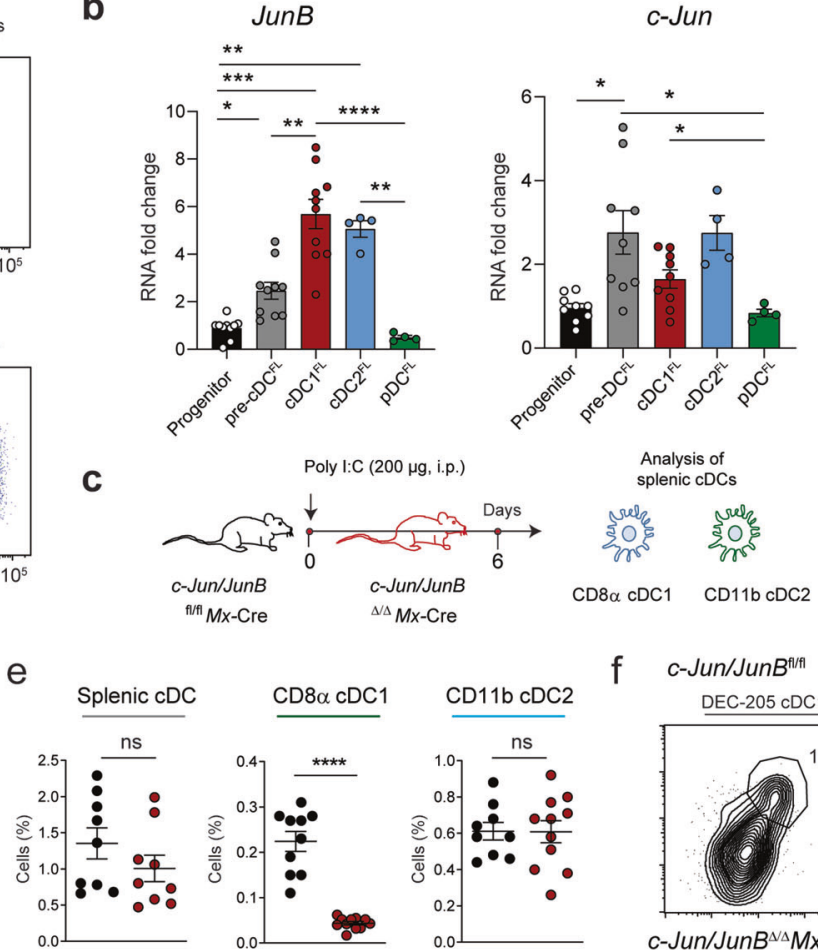

f c-Jun/JunB $B^{\text {ffrf }}$
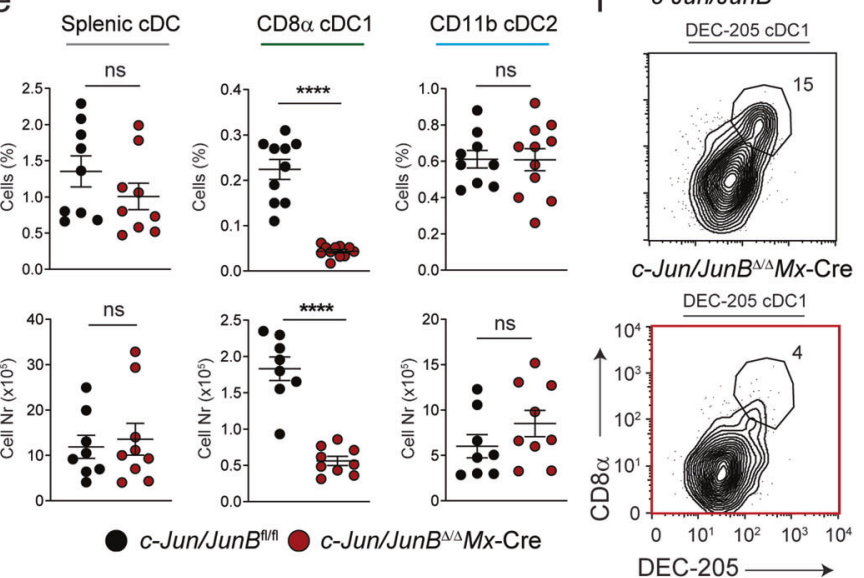

h
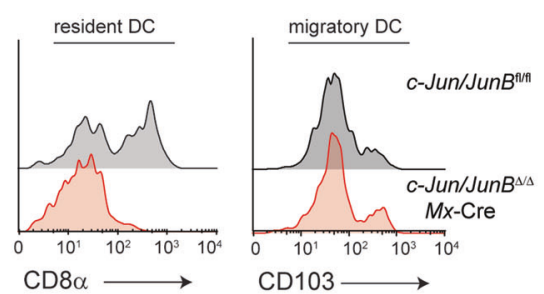

$\mathrm{CD} 8 \alpha \longrightarrow \mathrm{CD} 103 \longrightarrow$

i

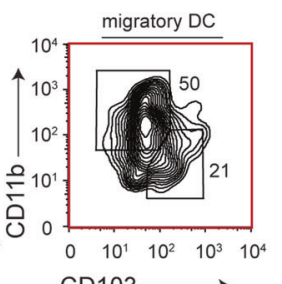

$\mathrm{CD} 103 \longrightarrow$

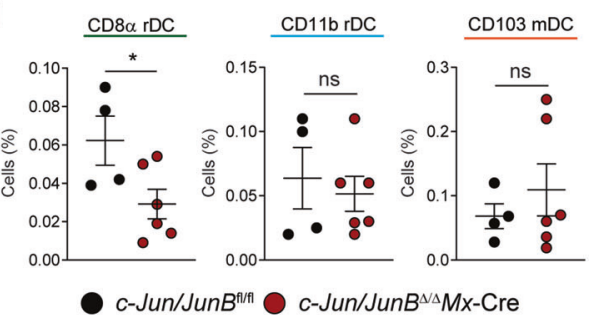

\section{Statistics}

GraphPad Prism 8 was used for statistical analysis. Significance was analyzed on pooled data from independent experiments. Animals were randomly assigned to experimental groups. Data were analyzed by unpaired two-tailed Students $t$ test or one-way ANOVA with Tukey post-test, or multiple $t$-tests with the Holm-Sidak method for grouped data and are shown as mean \pm SEM. $t$-test with Welch's correction was performed, if variance was significantly different between two sets of data. Outliers were identified by Grubb's or ROUT method. A $P$ value below 0.05 was considered statistically significant $(* P<0.05, * * P<0.01$, $* * * P<0.001, * * * * P<0.0001)$. 
Fig. 1 Combined deletion of c-Jun and JunB results in loss of resident $\mathrm{CD8} \alpha \mathrm{cDC1}$, while migratory $\mathrm{CD103}$ cDC1 remain unaffected. a Representative flow cytometry plots depict the sorting strategy for $\mathrm{pDCs}^{\mathrm{FL}}\left(\mathrm{CD} 11 \mathrm{c}^{+} \mathrm{B} 220^{+}\right)$, the $\mathrm{cDC}^{\mathrm{FL}}$ subsets $\left(\mathrm{CD} 11 \mathrm{c}^{+} \mathrm{I}-\mathrm{A} /\right.$ $\left.\mathrm{I}^{+} \mathrm{E}^{+}\right): \mathrm{cDC1}^{\mathrm{FL}}\left(\mathrm{CD} 24^{+} \mathrm{cDC}^{\mathrm{FL}}\right), \mathrm{cDC} 2^{\mathrm{FL}}\left(\mathrm{CD} 172 \mathrm{a}^{+} \mathrm{cDC}^{\mathrm{FL}}\right)$, pre-cDCs $^{\mathrm{FL}}$ (B220- $\left.\mathrm{CD} 117^{\text {low-int }} \mathrm{CD} 115^{+} \mathrm{CD} 11 \mathrm{c}^{+} \mathrm{I}-\mathrm{A} / \mathrm{I}-\mathrm{E}^{-}\right)$, and progenitors $\left(\mathrm{B} 220^{-}\right.$ $\left.\mathrm{CD} 117^{\text {low-int }} \mathrm{CD} 115^{+} \mathrm{CD} 11 \mathrm{c}^{-} \mathrm{I}-\mathrm{A} / \mathrm{I}-\mathrm{E}^{-}\right)$generated from wild-type bone marrow supplemented with FLT3L for 8d. b RT-qPCR analysis of $c$-Jun and JunB mRNA expression in progenitors, pre-cDC ${ }^{\mathrm{FL}}, \mathrm{cDCl}^{\mathrm{FL}}$, $\mathrm{cDC}^{\mathrm{FL}}, \mathrm{pDC}^{\mathrm{FL}}$. Subsets were obtained according to (a). RNA fold change is shown relative to the progenitor population. c Experimental design. Deletion of c-Jun and JunB in the $M x$-Cre mouse model was induced by injection of poly I: C (i.p., $200 \mu \mathrm{g}$ ). Mice were analyzed 6 days after the first injection. d Representative flow cytometry plots show single, live splenic $\mathrm{cDCs}\left(\mathrm{CD} 11 \mathrm{c}^{+} \mathrm{I}-\mathrm{A} / \mathrm{I}-\mathrm{E}^{+}\right)$and $\mathrm{CD} 8 \alpha \mathrm{cDC} 1$ $\left(\mathrm{CD} 8 \alpha^{+} \mathrm{CD} 11 \mathrm{~b}^{-} \mathrm{cDC}\right)$ and $\mathrm{CD} 11 \mathrm{~b} \mathrm{cDC} 2\left(\mathrm{CD} 8 \alpha^{-} \mathrm{CD} 11 \mathrm{~b}^{+} \mathrm{cDC}\right)$ subsets from indicated mice. e Frequency and number of splenic CD $8 \alpha$ cDC1 and $\mathrm{CD} 11 \mathrm{~b} \mathrm{cDC} 2$ as defined in (d) are shown. f Representative flow cytometry plots depict splenic $\mathrm{cDC} 1$ defined as DEC-205 ${ }^{+} \mathrm{CD} 11 \mathrm{c}^{+}$cells in control $c$-Jun/JunB ${ }^{\text {fl/fl }}$ and in $c$-Jun/JunB ${ }^{\Delta / \Delta} M x$-Cre mice. g Skindraining lymph node (sd-LN) cDCs consisting of migratory DCs (mDCs; $\mathrm{CD} 11 \mathrm{c}^{+} \mathrm{I}-\mathrm{A} / \mathrm{I}-\mathrm{E}^{\text {high }}$ ) and resident $\mathrm{DCs}\left(\mathrm{rDCs} ; \mathrm{CD} 11 \mathrm{c}^{+} \mathrm{I}-\mathrm{A} / \mathrm{I}-\mathrm{E}^{\mathrm{int}}\right.$ ) were analyzed by flow cytometry for the CD8 $\alpha \mathrm{rDC}$ and CD103 mDC subset in $c$-Jun/JunB ${ }^{\mathrm{f} / / \mathrm{ll}}$ and $c$-Jun/JunB ${ }^{\Delta / \Delta} \mathrm{Mx}$-Cre mice. h Flow cytometric histograms show $\mathrm{CD} 8 \alpha$ or CD103 expression on sd-LN cDCs $\left(\mathrm{CD} 11 \mathrm{c}^{+} \mathrm{I}-\right.$ $\left.\mathrm{A} / \mathrm{I}-\mathrm{E}^{\mathrm{int}-\mathrm{high}}\right)$ in the indicated mice. $\mathbf{i} \mathrm{rDCs}$ and $\mathrm{mDCs}$ from $(\mathbf{g})$ are shown as percentage of live, single cells. Data are representative of $2-5$ independent experiments. Dots indicate number of individual mice per experimental group. Error bars represent mean \pm SEM. Statistical significance was determined by Brown-Forsythe and Welch ANOVA test (b) and unpaired two-tailed Student's $t$ test $(\mathbf{e}, \mathbf{i}) . * * * * P<0.0001$, $* * * P<0.001, * * P<0.01, * P<0.05$ and $\mathrm{ns}>0.05$.

\section{Results}

\section{Combined deletion of $c-J u n$ and JunB results in loss of resident CD8a CDC1, while migratory CD103 CDC1 remain unaffected}

To study the role of Jun/AP-1 proteins during DC diversification, we first conducted an unbiased gene expression analysis of c-Jun and JunB across the immune cell compartment using IMMGEN datasets. We found prominent expression of c-Jun and JunB in cDCs, but not in pDCs (Supplementary Fig. 1a).

To confirm these results, FLT3L-derived cDCs $\left(\mathrm{cDCs}^{\mathrm{FL}}\right)$ were generated from $\mathrm{BM}$ to analyze the expression of c-Jun and JunB during DC development (Fig. 1a). RNA expression from sorted cell subpopulations revealed an increase in JunB expression from progenitors to $\mathrm{cDCs}^{\mathrm{FL}}$, whereas levels remained low in $\mathrm{pDCs}^{\mathrm{FL}}$. In contrast, c-Jun mRNA levels were highest in pre-cDCs ${ }^{\mathrm{FL}}$ and $\mathrm{cDC} 2^{\mathrm{FL}}$, intermediate in $\mathrm{cDC}^{\mathrm{FL}}$ and low in $\mathrm{pDC}^{\mathrm{FL}}$ (Fig. 1b). Analysis of c-Jun and JunB expression in cDCs, pre-cDCs and CDPs in vivo, using previously published microarray data [14], confirmed these results (Supplementary Fig. 1b).
To determine, whether these Jun/AP-1 factors are functionally involved in DC development, $c-J u n^{\mathrm{f} / \mathrm{fl}}$ and $J u n B^{\mathrm{f} / / \mathrm{l}}$ mice were crossed with $M x$-Cre mice allowing induction of Cre-recombinase in a diverse set of cells, including the hematopoietic stem cell compartment, by injection of poly I: C [31, 32, 34]. No differences in splenic $\mathrm{cDC} 1$ and $\mathrm{cDC} 2$ subsets, identified by $\mathrm{CD} 8 \alpha$ and CD11b marker expression among cDCs, were observed in $c$-Jun ${ }^{\Delta / \Delta} M x$-Cre and $J u n B^{\Delta / \Delta} M x$-Cre mice (Supplementary Fig. 1c-f). Thus, although c-Jun and JunB are induced during $\mathrm{CDC}$ development, these Jun/AP-1 proteins individually are dispensable for $\mathrm{CDC}$ diversification.

Closely related AP-1 proteins can functionally substitute for the absence of a family member during development and proliferation [24]. We speculated that c-Jun and JunB might compensate for each other, so that only combined deletion of both AP-1 factors would affect DC diversification.

Loss of c-Jun/JunB in $c$-Jun/Jun $B^{\Delta / \Delta} M x$-Cre mice (Fig. 1c) induced a dramatic reduction in the frequency and total cell number of splenic $\mathrm{CD} 8 \alpha \mathrm{cDC} 1$, whereas numbers of $\mathrm{CD} 11 \mathrm{~b}$ cDC2 were unchanged (Fig. 1d, e). DEC-205 expression correlates with CD8 $\alpha$ on cDC1s [41]. The DEC-205 ${ }^{+} \mathrm{CD} 11 \mathrm{c}^{+}$ population in $c$-Jun/Jun $B^{\Delta / \Delta} M x$-Cre mice was reduced, confirming that the observed phenotype in $\mathrm{cDC} 1$ cells was not caused by down-regulation of CD $8 \alpha$ on cDCs (Fig. 1f). Moreover, changes in the splenic immune cell compartment, in particular myeloid cells $\left(\mathrm{CD} 11 \mathrm{~b}^{+} \mathrm{Ly}-6 \mathrm{C} / \mathrm{G}^{+}\right)$, could be observed. The frequency of splenic B and $\mathrm{T}$ cells was altered, the absolute number, however, was not affected (Supplementary Fig. 2a, b). Interestingly, these observed changes in the immune cell composition preceded a more severe phenotype that developed within 2-3 weeks of Cre recombinase induction and included an inflamed skin (Supplementary Fig. 2c), weight loss and increased mortality (data not shown).

We then examined cDC populations in skin-draining lymph-nodes (sd-LN) of $c$-Jun $/ \operatorname{Jun}^{\Delta / \Delta} M x$-Cre. Reduced populations of both lymphoid-resident (CD8 $\alpha)$ and migratory (CD103) cDC1 have been reported in IRF8- and Batf3deficient mice [42]. However, in $c$-Jun $/ J u n B^{\Delta / \Delta} M x$-Cre mice only the resident $\mathrm{CD} 8 \alpha \mathrm{CDC} 1$ population was significantly reduced (Fig. 1g-i).

In c-Jun/Jun $B^{\Delta / \Delta} M x$-Cre mice deletion of c-Jun/JunB occurs already in hematopoietic stem cells and might affect the commitment of multipotent progenitors to a single fate. We detected a significant expansion of granulocytemacrophage progenitors (GMPs) in the BM of $c-J u n / J u n B^{\Delta /}$ ${ }^{\Delta} M x$-Cre mice, whereas progenitors, precursors of cDCs and lymphocytes were unchanged (Supplementary Fig. 2d-f).

To better characterize cDC development from BM progenitors, we cultured c-Jun/JunB deficient BM cells supplemented with FLT3L. We observed prominent defects in 
a
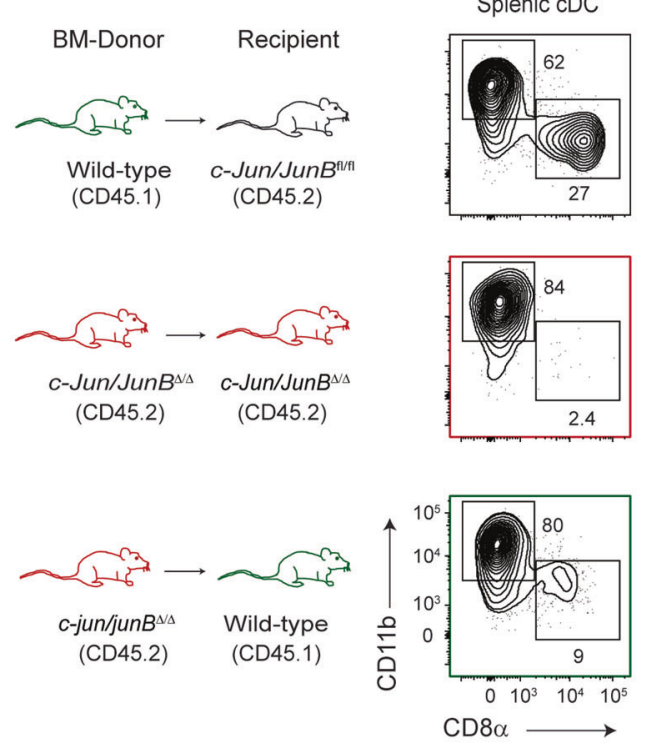

d

C-Jun/JunB ${ }^{+/+}(C D 45.1 / 2)+c-J u n / J u n B^{n / 1 / 1}(C D 45.2)$

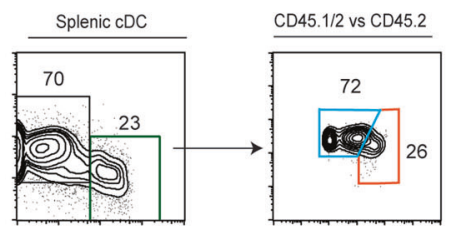

C-Jun/JunB ${ }^{+/+}\left(\right.$CD45.1/2) + c-Jun/JunB ${ }^{N / \Delta}($ CD 45.2)

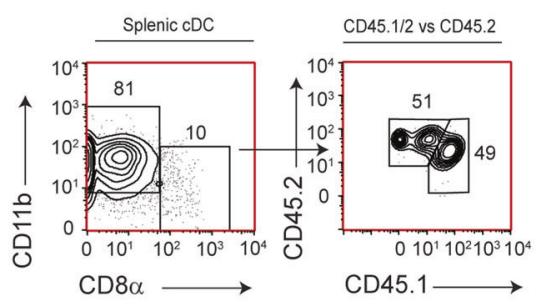

f

Blocking G-CSF signalling

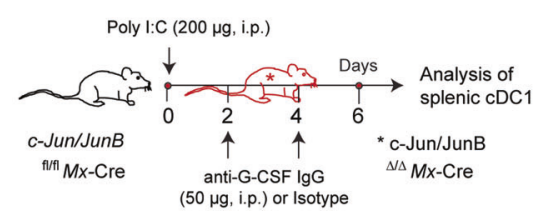

b

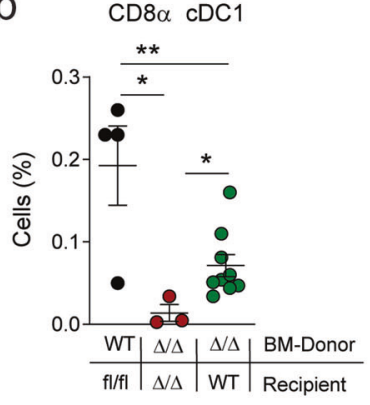

C

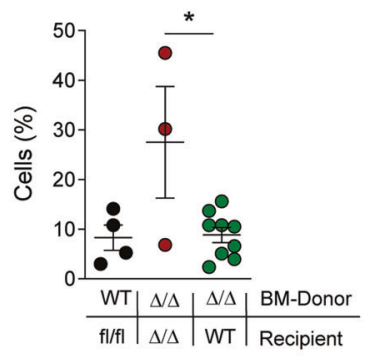

e $\mathrm{CD} 8 \alpha \mathrm{cDC} 1$ CD45.1/2 $\square$ CD45.2
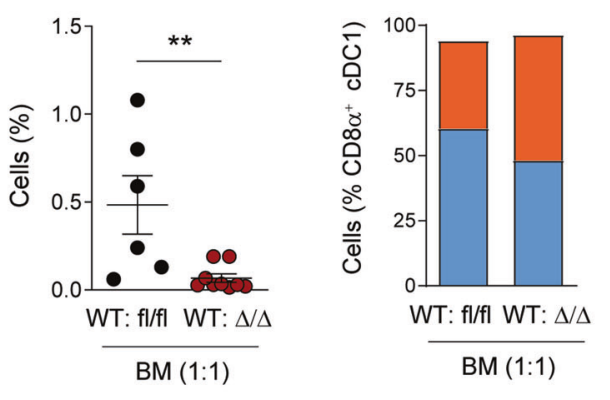

9

$\mathrm{CD} 8 \alpha \mathrm{CDC} 1$

Neutrophils
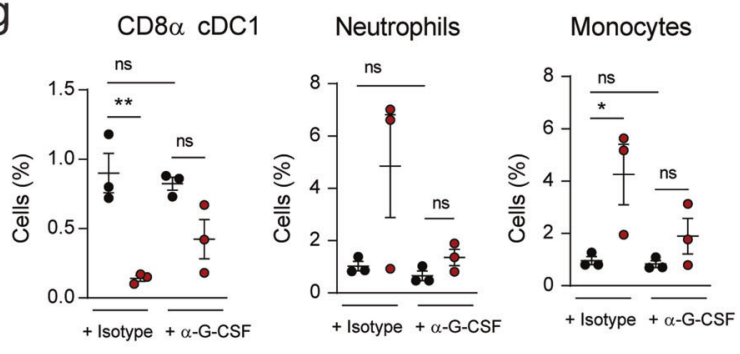

c-Jun/JunB $B^{\mathrm{t} / 1 / 1}$

c-Jun/JunB ${ }^{\Delta \Delta} M x-C r e$

\section{Intrinsic and extrinsic factors determine the fate of CD8a CDC1 in C-Jun/Jun $B^{\Delta / \Delta} M x-C r e$ mice}

To determine, if the diminished $\mathrm{CD} 8 \alpha \mathrm{cDC} 1$ population in $c$-Jun $/ J u n B^{\Delta / \Delta} M x$-Cre mice was due to cell-intrinsic effects of c-Jun/JunB in DCs or a consequence of extrinsic c-Jun/ 
Fig. 2 Intrinsic and extrinsic factors determine the fate of CD8 $\alpha$ cDC1 in $\boldsymbol{c}$-Jun/JunB $\boldsymbol{B}^{\mathbf{\Delta} \boldsymbol{\Delta}} \boldsymbol{M} \boldsymbol{x}$-Cre mice. a Experimental design and representative flow cytometry plots of splenic $\mathrm{cDCs}\left(\mathrm{CD} 11 \mathrm{c}^{+} \mathrm{I}-\mathrm{A} / \mathrm{I}-\mathrm{E}^{+}\right)$ for the different BM chimeras are shown. Donor BM $\left(2-4 \times 10^{6}\right)$ of the indicated genotypes was injected i.v. into lethally irradiated wild-type, $c-J u n / J u n B^{\mathrm{f} / \mathrm{fl}}$ and $c$-Jun $/$ Jun $B^{\mathrm{f} / \mathrm{fl}} M x$-Cre recipient mice. Deletion was induced by injection of poly I: $\mathrm{C}$ ( 2 times, 5 days apart) and mice were analyzed 14 days after. b-c Splenic CD8 $\alpha$ cDC1 $\left(\mathrm{CD} 11 \mathrm{c}^{+} \mathrm{CD} 8 \alpha^{+}\right)(\mathbf{b})$ and $\mathrm{CD} 11 \mathrm{~b}$ cells $\left(\mathrm{CD} 11 \mathrm{~b}^{+}\right)(\mathbf{c})$ were analyzed by flow cytometry in BM chimeras described in (a). d Representative flow cytometry plots show splenic cDCs generated from mixed BM chimeras. Wild-type, CD45.1 and CD45.2 expressing BM, was mixed in a 1:1 ratio with CD45.2 c-Jun/JunB $B^{\mathrm{f} / \mathrm{fl}}$ or $c$-Jun $/$ Jun $^{\mathrm{f} / / \mathrm{f}} M x$-Cre BM. Deletion was induced by injection of poly I: C ( 2 times, 5 days apart) and mice were analyzed 14 days after. e Splenic cDCs from (d) were analyzed for the percentage of $\mathrm{CD} 8 \alpha \mathrm{cDC} 1\left(\mathrm{CD} 11 \mathrm{c}^{+} \mathrm{CD} 8 \alpha^{+}\right)$(left) and their expression of CD45.1/2 or CD45.2 (right). f Scheme depicting the treatment to neutralize G-CSF signaling in $c$-Jun/Jun $B^{\Delta / \Delta} M x$-Cre mice. Cre recombinase was induced by injection of poly I: C ( $200 \mu$ g, i.p.). AntiG-CSF IgG antibodies (50 $\mu$ g, i.p.) were injected 2 and 4 days after deletion of c-Jun/JunB. Isotype was injected in controls. Analysis of splenic $\mathrm{cDC} 1$ and myeloid cells was done on day 6 post poly I: C injection. g Splenic CD8 $\alpha$ cDC1 $\left(\mathrm{CD} 11 \mathrm{c}^{+} \mathrm{MHCII}^{+} \mathrm{XCR} 1^{+} \mathrm{CD} 8 \alpha^{+}\right)$, monocytes $\left(\right.$ Ly6-C ${ }^{+} \mathrm{CD} 11 \mathrm{~b}^{+}$) and neutrophils $\left(\mathrm{Ly}_{6} \mathrm{G}^{+} \mathrm{CD} 11 \mathrm{~b}^{+}\right)$were analyzed in mice of the indicated genotype treated as described in (f). Data are representative of 1-3 independent experiments. Flow cytometry plots shown are pre-gated on single, live cells. Dots indicate number of individual mice per experimental group. Error bars represent mean \pm SEM. Statistical significance was determined by unpaired twotailed Student's $t$ test (b, $\mathbf{c}$ and $\mathbf{e}$ ) and one-way ANOVA with Tukey post-test $(\mathbf{g}) . * * P<0.01, * P<0.05$ and ns $>0.05$.

JunB dependent signals BM chimeras were generated. Loss of c-Jun/JunB only in hematopoietic cells partially rescued the splenic $\mathrm{CDC} 1$ phenotype after Cre recombinase activation, when compared to control mice (Fig. 2a, b). Thus, extrinsic and intrinsic factors are critical for CD8 $\alpha$ cDC1 specification. In contrast, the increase in myeloid cells was rescued, if c-Jun/JunB was deleted only in BM cells (Fig. 2c).

To specify, if extrinsic signals from hematopoietic cells determine $\mathrm{CD} 8 \alpha \mathrm{cDC} 1$ fate competitive, mixed $\mathrm{BM}$ chimeras were generated by giving wild-type (CD45.1/2) and $c$-Jun/JunB $B^{\mathrm{f} / \mathrm{fl}}$ or $c$-Jun/JunB $B^{\mathrm{f} / \mathrm{fl}} M x$-Cre (CD45.2) BM cells in a ratio of $1: 1$ into $c$-Jun/JunB $B^{\mathrm{f} / \mathrm{fl}}$ mice. After recombination by poly $\mathrm{I}: \mathrm{C}$, the overall frequency of $\mathrm{CD} 8 \alpha \mathrm{cDC} 1$ was significantly reduced in mice harboring wild-type and $c$-Jun $/ J u n B^{\Delta / \Delta} M x$-Cre BM (Fig. 2d, e, left panel). The few remaining $\mathrm{CD} 8 \alpha$ cDC1 were equally derived from both, wild-type and c-Jun/JunB-deficient BM (Fig. 2e, right panel).

Among other organs $M x$-Cre activation also results in genomic recombination in skin cells. To investigate, whether extrinsic factors influence $\mathrm{CD} 8 \alpha \mathrm{cDC} 1$ differentiation we used a mouse model with deletion of c-Jun/JunB restricted to keratinocytes $\left(c-J u n / J u n B^{\Delta / \Delta} K 5-\mathrm{Cre}^{\mathrm{ER}}\right)$ that results in a psoriasis-like skin inflammation [25, 43]. Splenic CD8 $\alpha$ cDC1 were diminished in $c-J u n / J u n B^{\Delta / \Delta} K 5-\mathrm{Cre}^{\mathrm{ER}}$ mice, although not to the extent as in $c$-Jun/JunB ${ }^{\Delta / \Delta} M x$-Cre mice (Supplementary Fig. 3a-c). In contrast, we did not observe a reduction in the Imiquimod induced psoriasis-like skin inflammation model (Supplementary Fig. 3d, e).

G-CSF, a JunB target gene [44], has been shown to influence cDC1 development [45]. To test the role of G-CSF signaling in our observed phenotype, we treated c-Jun $/ J u n B^{\Delta / \Delta} M x$-Cre with anti-G-CSF neutralizing antibodies in vivo (Fig. 2f). We found that suppression of G-CSF signaling partially restored splenic $\mathrm{cDC} 1$ in $c$ $J u n / J u n B^{\Delta / \Delta} M x$-Cre mice and normalized the frequency of monocytes and neutrophils (Fig. 2g).

In summary, these data show that extrinsic and intrinsic mechanisms controlled by c-Jun/JunB have synergistic effects and together cause a severe reduction of $\mathrm{cDC} 1$ in $c$ Jun/JunB ${ }^{\Delta / \Delta} M x$-Cre mice.

\section{c-Jun and JunB coordinate CDC1 subset differentiation under homeostatic conditions}

To further investigate the cell-intrinsic function of c-Jun/JunB within committed cDCs, we conditionally inactivated c-Jun/ JunB in all CD11 $\mathrm{c}^{+}$cells by crossing $c$-Jun/JunB ${ }^{\mathrm{f} / \mathrm{fl}}$ into Itgax (CD11c)-Cre mice. Deletion of c-Jun/JunB in CD11 $\mathrm{c}^{+}$cells did not lead to any apparent inflammatory phenotype. Adult c-Jun/JunB ${ }^{\Delta / \Delta}$ Itgax -Cre mice ( $<8$ weeks) showed normal frequencies of B cells, CD4 and CD8 T cells, myeloid cells, NK-cells and pDCs in the spleen (Supplementary Fig. 4a). However, loss of c-Jun/JunB at the pre-cDC stage induced a significant reduction of $\mathrm{CD} 8 \alpha \mathrm{cDC} 1$ (Fig. 3a, b) implying a phenotype similar to $c$-Jun $/ J u n B^{\Delta / \Delta} M x$-Cre mice. The overall reduction in $\mathrm{CD} 8 \alpha \mathrm{CDC} 1$ was less severe than in $c-J u n / J u n B^{4 /}$ ${ }^{\Delta} M x$-Cre mice and more comparable to WT $+\Delta / \Delta$ BM chimeras (Fig. 2b). Other markers (XCR1, CD24 and DEC-205) [6] that identify the splenic $\mathrm{cDC} 1$ subset were diminished in the spleen, while the frequency of CD11b cDC2 was not altered (Fig. 3a, b, Supplementary Fig. 4b). Consistent to our data in the $M x$-Cre mouse model, skin-draining LNs of $c$ Jun/JunB $B^{\Delta / \Delta}$ Itgax -Cre mice showed a reduced number of $\mathrm{CD} 8 \alpha \mathrm{rDC}$, whereas the CD103 mDC subset was not affected (Fig. 3c, d). Moreover, c-Jun/JunB ${ }^{\Delta / \Delta}$ Itgax-Cre mice showed normal development of cDC- and myeloid progenitors in the $\mathrm{BM}$, including pre-cDC1 and pre-cDC2 subpopulations (Supplementary Fig. 4c-e). These results further support our hypothesis that c-Jun and JunB together promote the differentiation of pre-cDCs to $\mathrm{cDC} 1 \mathrm{~s}$ under homeostatic conditions.

In vitro, significantly less $\mathrm{cDC} 1^{\mathrm{FL}}$ developed from $c$-Jun/ $J u n B^{\Delta / \Delta}$ Itgax-Cre BM. However, a prominent CD24 $4^{\text {int }}$ population was seen in $c$-Jun/JunB ${ }^{\Delta / \Delta}$ Itgax-Cre FLT3L BM cultures that lacked expression of typical DC markers, like $\mathrm{XCR} 1$ or MHC-II, resembling an immature $\mathrm{CDC}^{\mathrm{FL}}$ population (Fig. 3e-f). In contrast, normal differentiation of 
a

C-Jun/JunB $B^{\text {In/n }}$

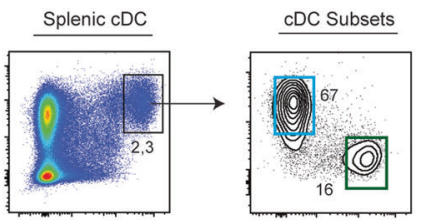

c-Jun/JunB ${ }^{\Delta \Delta}$ Itgax-Cre $^{-}$
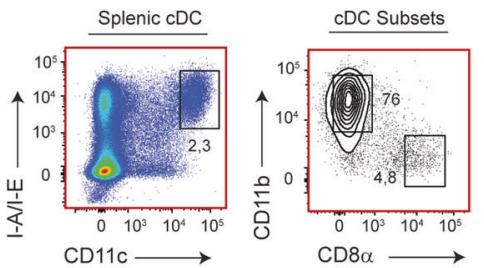

C

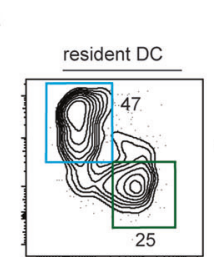

c-Jun/JunB $B^{\text {t/n }}$

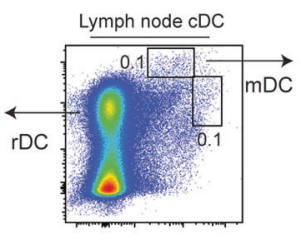

c-Jun/JunB $B^{N /}$ Itgax-Cre
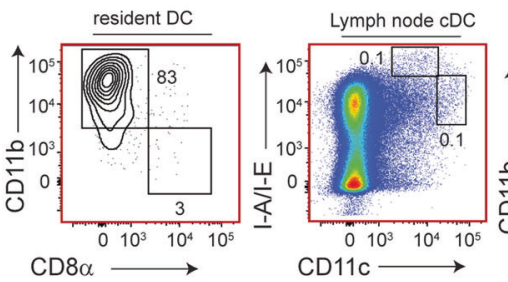

e

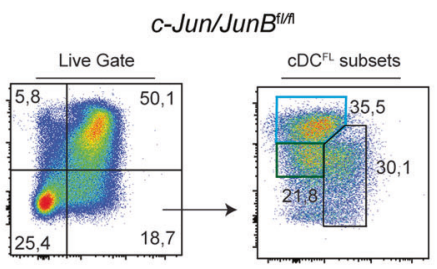

c-Jun/JunB ${ }^{\Delta / \Delta}$ Itgax-Cre
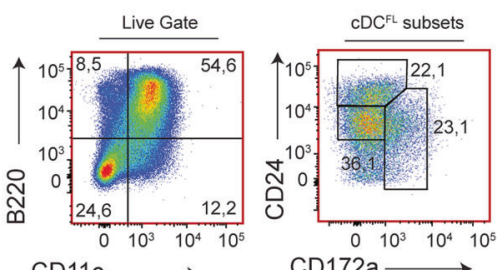

$\mathrm{CD} 11 \mathrm{c} \longrightarrow$

b

f
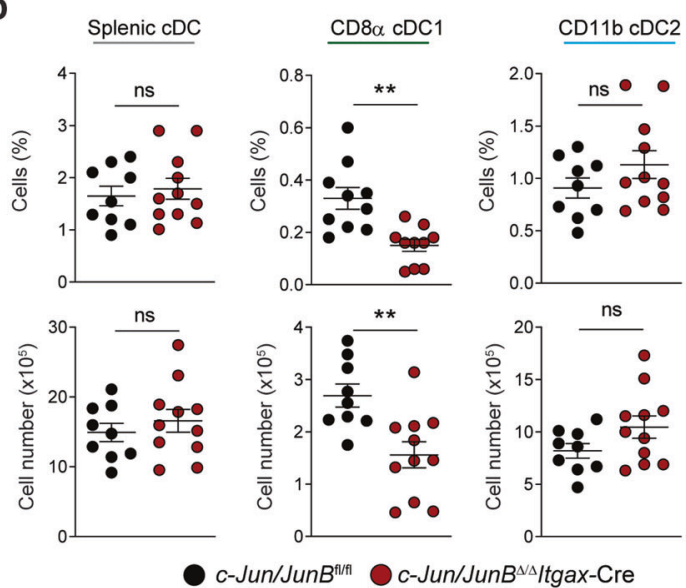

$c-J u n / J u n B^{n / 1} \bigcirc$ c-Jun/JunB $B^{\Delta \Delta} / \operatorname{tgax}-\mathrm{Cre}$

d
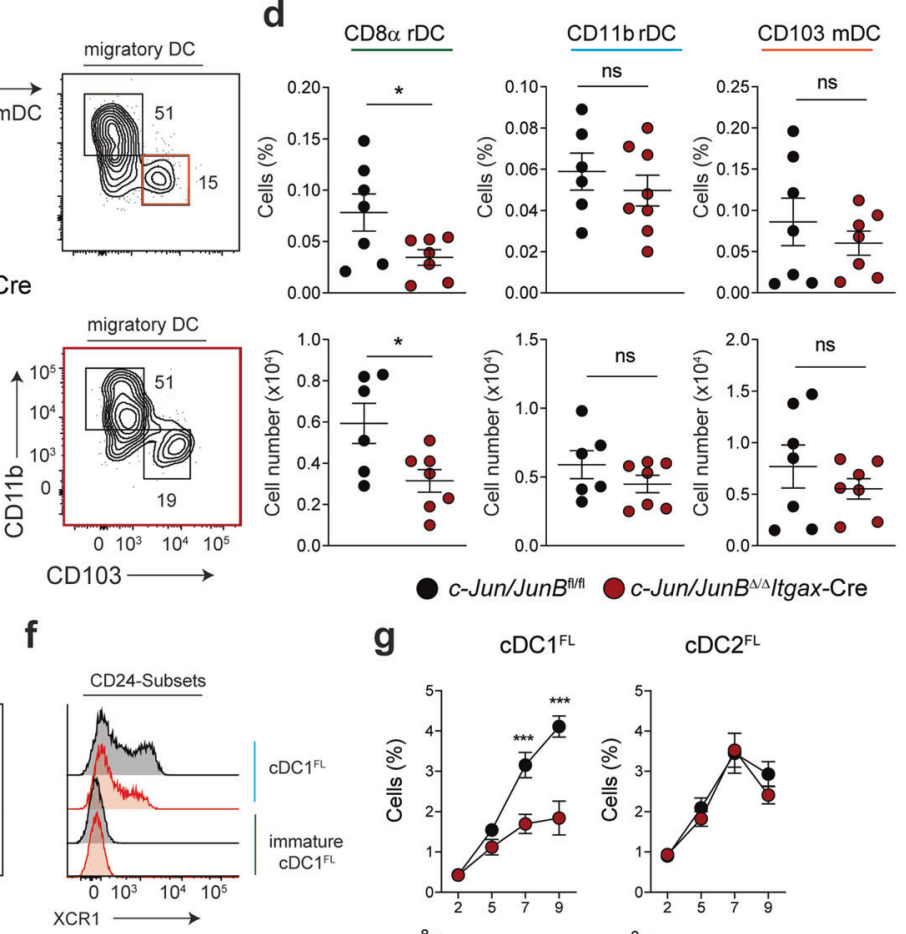

g

$\mathrm{CDC} 1^{\mathrm{FL}}$

$\mathrm{CDC} 2^{\mathrm{FL}}$
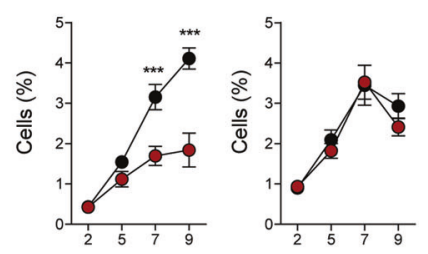

CD24-Subsets
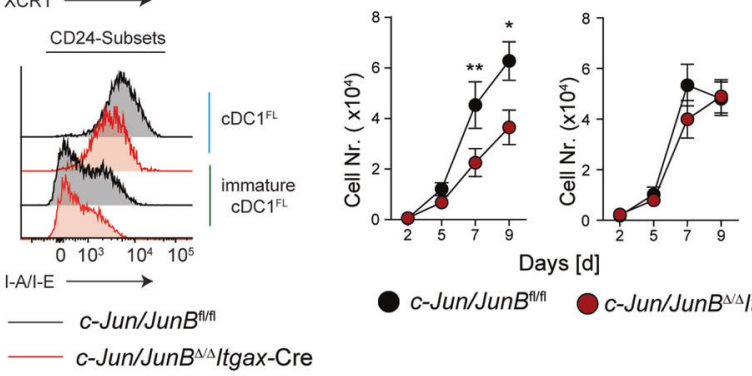

C-Jun/JunB ${ }^{\text {fi/f }}$

c-Jun/JunB $B^{\wedge /} /$ tgax-Cre
$\mathrm{cDC}^{\mathrm{FL}}, \mathrm{pDC}^{\mathrm{FL}}$ and $\mathrm{CDP}^{\mathrm{FL}}$ populations was observed, whereas pre-cDCs ${ }^{\mathrm{FL}}$ were reduced after one week of culture (Fig. 3e, g and Supplementary Fig. 4f, g). Thus, c-Jun/JunB are required cell-intrinsically to orchestrate the final step of $\mathrm{cDC} 1$ development, the transition of pre-cDCs to $\mathrm{cDC} 1$, both in vitro and in vivo.

\section{GM-CSF signaling secures development of c-Jun/ JunB-deficient CD103 CDC1}

Next, we analyzed cDCs in the skin, which contains two distinct $\mathrm{CDC} 1$ subsets with a $\mathrm{CD} 103^{-}$or $\mathrm{CD}_{103^{+}}$phenotype [46]. We found that cutaneous $\mathrm{CD}_{103}{ }^{-} \mathrm{cDC} 1$ were 
Fig. 3 c-Jun and JunB coordinate cDC1 subset differentiation under homeostatic conditions. a Spleen from $c$-Jun/JunB $B^{\mathrm{f} / \mathrm{fl}}$ and $c$ Jun/JunB $B^{\Delta / \Delta}$ Itgax-Cre mice was analyzed by flow cytometry for cDCs $\left(\mathrm{CD} 11 \mathrm{c}^{+} \mathrm{I}-\mathrm{A} / \mathrm{I}-\mathrm{E}^{+}\right), \mathrm{CD} 8 \alpha \mathrm{cDC} 1\left(\mathrm{CD} 8 \alpha^{+} \mathrm{CD} 11 \mathrm{~b}^{-} \mathrm{cDC}\right)$, and $\mathrm{CD} 11 \mathrm{~b}$ cDC2 $\left(\mathrm{CD} 8 \alpha^{-} \mathrm{CD} 11 \mathrm{~b}^{+} \mathrm{cDC}\right)$. b Frequency and total numbers of splenic cDC subsets described in (a) are shown. $\mathbf{c}$ Representative flow cytometry plots of resident $\left(\mathrm{CD} 11 \mathrm{c}^{+} \mathrm{I}-\mathrm{A} / \mathrm{I}-\mathrm{E}^{\text {int }}\right)$ and migratory DCs $\left(\mathrm{CD} 11 \mathrm{c}^{+} \mathrm{I}-\mathrm{A} / \mathrm{I}-\mathrm{E}^{\text {high }}\right)$ in skin-draining lymph nodes (sd-LN) of indicated mice are shown. d Frequency and total number of $\mathrm{CD} 8 \alpha \mathrm{rDC}$, CD11b rDC and CD103 mDC sd-LN cDC subsets described in (c) are shown. e Representative flow cytometry plots of $\mathrm{CDC1}^{\mathrm{FL}}$ $\left(\mathrm{B} 220^{-} \mathrm{CD} 11 \mathrm{c}^{+} \mathrm{CD} 24^{+}\right)$, immature $\mathrm{cDC}^{\mathrm{FL}}\left(\mathrm{B} 220^{-} \mathrm{CD} 11 \mathrm{c}^{+} \mathrm{CD} 24^{\text {int }}\right)$ and $\mathrm{CDC} 2^{\mathrm{FL}}\left(\mathrm{B} 220^{-} \mathrm{CD} 11 \mathrm{c}^{+} \mathrm{CD} 172 \mathrm{a}^{+}\right)$in FLT3L-supplemented BM cultures of $c$-Jun/JunB $B^{\mathrm{f} / \mathrm{fl}}$ and $c$-Jun $/$ JunB $^{\Delta / \Delta}$ Itgax-Cre mice on day 7. f Histograms show XCR1 and I-A/I-E expression on $\mathrm{CDC}^{\mathrm{FL}}$ and immature $\mathrm{cDC} 1^{\mathrm{FL}}$ as defined in (e). $\mathbf{g}$ Frequency and total number of $\mathrm{CDC}^{\mathrm{FL}}$ and $\mathrm{cDC} 2^{\mathrm{FL}}$ in FLT3L-supplemented BM cultures over time. ( $n=6-12$ per subgroup). Data are representative of 2-4 independent experiments. Flow cytometry plots shown are pre-gated on single, live cells. Dots indicate number of individual mice per experimental group. Error bars represent mean \pm SEM. Statistical significance was determined by unpaired two-tailed Student's $t$ test $(\mathbf{b}, \mathbf{d}$ and $\mathbf{g})$. $* * * P<$ $0.001, * * P<0.01, * P<0.05$ and $\mathrm{ns}>0.05$.

reduced in $c$-Jun $/$ JunB $^{\Delta / \Delta}$ Itgax-Cre mice, whereas $\mathrm{CD} 103^{+}$ cDC1, cDC2 and Langerhans cells (LCs) were unchanged (Fig. 4a, b). Next, we analyzed lung and colon, two nonlymphoid tissues that contain a prominent CD103 cDC1 population. We observed no difference in CD103 cDC1 cells in $c$-Jun/JunB ${ }^{\Delta / \Delta}$ Itgax-Cre compared to control mice (Supplementary Fig. 5a, b). GM-CSF controls nonlymphoid CD103 cDC1 development [47] and is used for the efficient generation of $\mathrm{CD} 103 \mathrm{cDC} 1$ from $\mathrm{BM}$ in vitro [48]. We therefore next analyzed $\mathrm{CD}_{103^{-}}$and $\mathrm{CD} 103^{+}$ cDC1 generated from BM cultures supplemented with FLT3L alone or in combination with GM-CSF. cDCs deficient in c-Jun/JunB showed a decreased frequency in $\mathrm{CD}_{103^{-}} \mathrm{cDC}^{\mathrm{FL}}$, whereas $\mathrm{CD} 103^{+} \mathrm{cDC}^{\mathrm{FL}}$ and $\mathrm{CD} 103^{+}$ $\mathrm{CDCl}^{\mathrm{FL}+\mathrm{G}}$ were comparable to the control (Fig. 4c, d). These data show that the GM-CSF-dependent CD103 cDC1 subset develops normally in $c$-Jun/JunB ${ }^{\Delta / \Delta}$ Itgax-Cre mice.

\section{Global transcriptional changes in c-Jun/JunB deficient CDC1}

Next, we performed RNA sequencing to characterize the transcriptional profile in C-Jun/JunB deficient $\mathrm{CDC} 1$ in an unbiased manner. We compared in vitro generated $\mathrm{CDC} 1 \mathrm{~s}^{\mathrm{FL}}$ from $c$-Jun/JunB $B^{\Delta / \Delta}$ Itgax -Cre to $c$-Jun/JunB ${ }^{\mathrm{t} / \mathrm{fl}}$ mice and found 432 genes to be differentially expressed (Supplementary Table 3). Gene ontology (GO) term analysis of the DEGs revealed down-regulation of genes linked to antiviral responses, like double-stranded RNA binding and $2^{\prime}-5^{\prime}$ oligoadenylatesynthetase in c-Jun/JunB-deficient $\mathrm{cDC} 1 \mathrm{~s}^{\mathrm{FL}}$, whereas genes linked to cell surface expression, enabling carbohydrate binding or detection of external stimuli, were up-regulated (Fig. 5a). Principal component analysis (PCA) further confirmed a clear segregation of c-Jun/JunB-deficient $\mathrm{cDC} 1 \mathrm{~s}^{\mathrm{FL}}$ from control cDCs (Fig. 5b) and GSEA showed significant enrichment of $\mathrm{CDC} 1$ specific gene sets in the control only (Fig. 5c). Moreover, previously identified cDC1-specific genes (e.g., Ifi205, Rab7b, Snx22, Tlr3, Wdfy4 and Xcrl) $[49,50]$ were all reduced in c-Jun/JunBdeficient $\mathrm{cDC}^{\mathrm{FL}}{ }^{\mathrm{FL}}$ (Fig. 5d). Among the top-ranked DEGs we found genes that are involved in functional processes, like the prostaglandin inactivating enzyme $\mathrm{Hpgd}$, or a protease, Ctse, involved in antigen processing, a gene related to glycolysis (Enolb), to interferon-signaling (Ifi44l) and an uncharacterized zinc finger transcription factor (Zfp990) (Fig. 5e).

To define genes that are common or unique to c-Jun/ JunB, we compared our RNA-Seq data to published microarray data of $\mathrm{Batf}^{-/-} \mathrm{cDCl}$ (Batf3 genes) and Irf4 ${ }^{-/-}$Irf $^{-/-} \mathrm{cDC1}^{\mathrm{FL}}$ with restored IRF8 expression (IRF8 genes) [28, 49]. Among others, transcripts for the cDC2associated TFs Irf4, Klf4 and Ehf [51] were increased in both c-Jun/JunB and Batf3 deficient $\mathrm{CDC} 1$, whereas transcripts associated with $\mathrm{cDC} 1(\operatorname{Snx} 22, \mathrm{Tlr} 3, \mathrm{Xcr} 1)$ or cellular signaling (Plcel, Plpp1, Sppl, Fzd1) were reduced (Fig. 5f and Supplementary Table 4). Similar overlaps were observed comparing c-Jun/JunB to IRF8-dependent transcripts (Fig. 5g and Supplementary Table 5). These results show that c-Jun/JunB play an essential role to promote the gene expression in $\mathrm{cDC} 1$.

\section{CDC1 lacking C-Jun/JunB are functionally impaired in immune defense mechanisms}

Our RNA-Seq analysis highlighted a role for c-Jun/JunB in the expression of genes (Tlr3, Wdfy4) and pathways (dsRNA binding) associated with $\mathrm{cDC} 1$ function. Hence, we next investigated, whether these transcriptional changes impaired typical immune-functions of $\mathrm{cDC} 1$ in vivo and in vitro.

Importantly, we found that splenic $\mathrm{CD} 8 \alpha \mathrm{cDC} 1$ and in vitro generated $\mathrm{CDC} 1^{\mathrm{FL}}$ lacking c-Jun/JunB expressed significantly less IL-12p40 and failed to up-regulate the co-stimulatory molecules CD80 and CD86 after stimulation with the TLR3 ligand poly I: C (Fig. 6a-c, Supplementary Fig. 5c-d). Moreover, antigen crosspresentation was impaired in the absence of c-Jun/JunB in $\mathrm{cDCs}^{\mathrm{FL}}$ and a significantly reduced antigen-specific (Ovalbumin) CD8 $\alpha$ OT-I $\mathrm{T}$ cell proliferation was induced, when compared to control (Fig. 6d, e). CD8 $\alpha$ cDC1 have been shown to be a cellular entry point for infection with Listeria monocytogenes [52]. We observed a significantly reduced pathogen burden in the spleen and liver of $c$-Jun/JunB ${ }^{\Delta / \Delta}$ Itgax-Cre mice infected with 
a

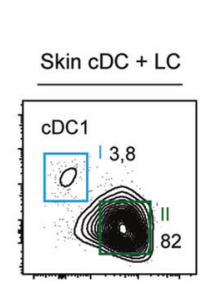

C-Jun/JunB $B^{\text {firf }}$

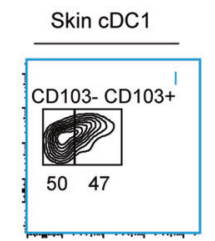

c-Jun/JunB $B^{\Delta \Delta}$ ltgax-Cre

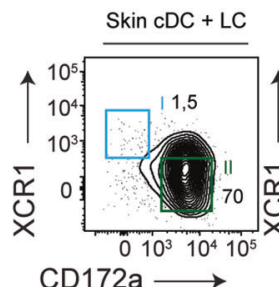

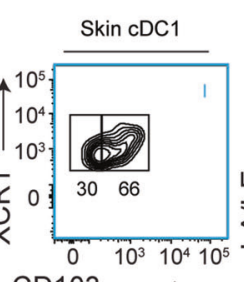

$\mathrm{CD} 103 \stackrel{\longrightarrow}{\longrightarrow}$

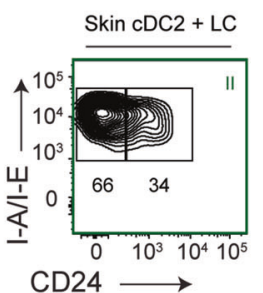

$\mathrm{CD} 24 \longrightarrow$
C c-Jun/JunB $B^{\text {frff }}$ b
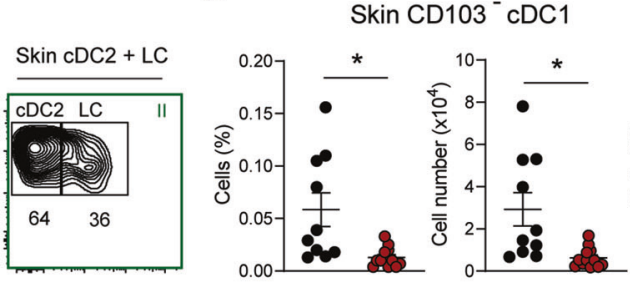

Skin $\mathrm{CDC} 2$
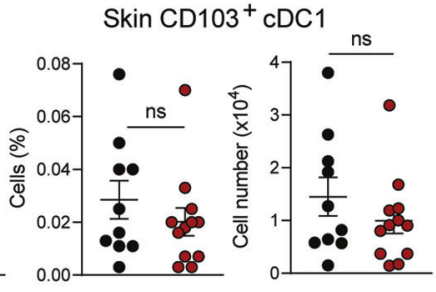

Skin LC

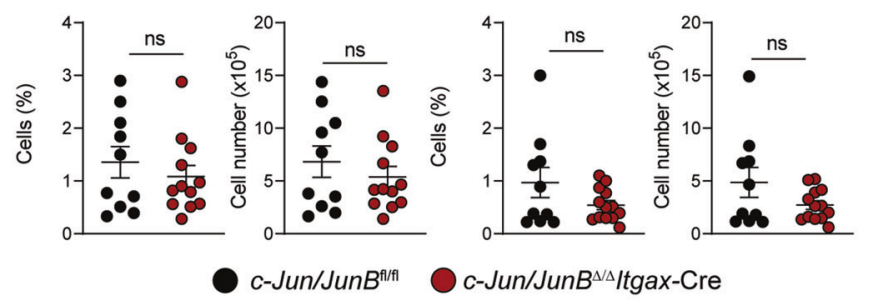

d
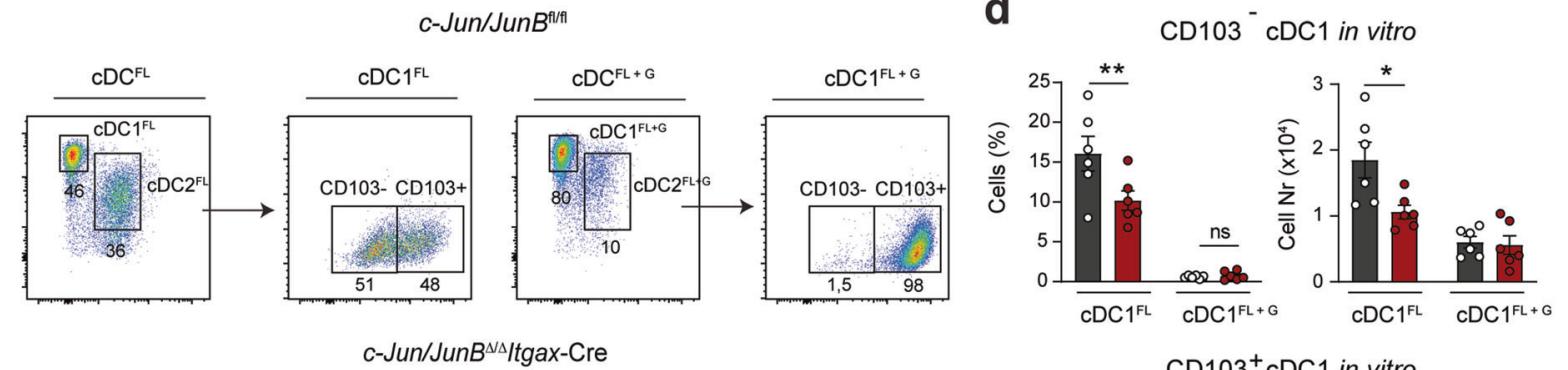
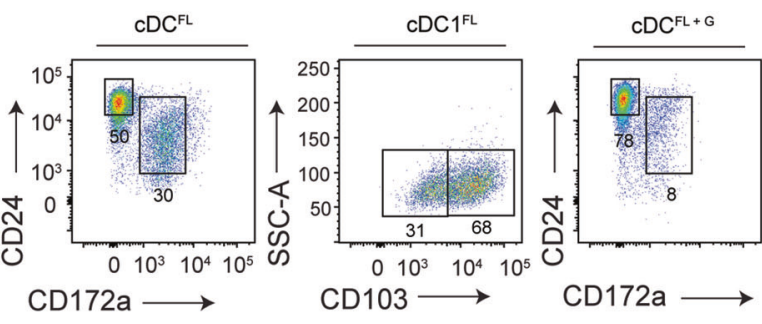

Fig. 4 GM-CSF signaling secures development of c-Jun/JunBdeficient CD103 cDC1. a Skin from $c$-Jun/JunB $B^{\mathrm{f} / \mathrm{fl}}$ and $c$-Jun/ $J u n B^{\Delta / \Delta}$ Itgax-Cre mice was analyzed by flow cytometry for cDCs $\left(\mathrm{CD} 45^{+} \mathrm{CD}^{-} 4^{-} \mathrm{CD} 11 \mathrm{c}^{+} \mathrm{I}-\mathrm{A} / \mathrm{I}_{-} \mathrm{E}^{+}\right), \mathrm{CD} 103^{-} \mathrm{cDC} 1$ XCR $^{+} \mathrm{CD} 103^{-}$ $\left.\mathrm{CD} 11 b^{-} \mathrm{cDCs}\right), \mathrm{CD}_{103}{ }^{+} \mathrm{cDC} 1$ (XCR1 $\left.^{+} \mathrm{CD}_{103}{ }^{+} \mathrm{CD} 11 \mathrm{~b}^{-} \mathrm{cDCs}\right)$, $\mathrm{cDC} 2\left(\mathrm{XCR}^{-}{ }^{-} \mathrm{CD} 11 \mathrm{~b}^{+} \mathrm{CD} 24^{-} \mathrm{cDCs}\right)$ and $\mathrm{LCs}\left(\mathrm{XCR} 1^{-} \mathrm{CD} 11 \mathrm{~b}^{+}\right.$ $\mathrm{CD} 24^{+} \mathrm{cDCs}$ ). Representative plots are shown and graphs are pregated on single, live cell populations. b Frequency and total numbers of cutaneous $\mathrm{CD}_{103^{-}}$and $\mathrm{CD}_{103^{+}} \mathrm{cDC} 1$, cDC2 and LCs as defined in (a) are shown. c Representative flow cytometry plots of cDCs $\left(\mathrm{B} 220^{-} \mathrm{Gr}-1^{-} \mathrm{CD} 11 \mathrm{c}^{+} \mathrm{MHC}^{-\mathrm{II}^{+}}\right.$) generated from FLT3L

L. monocytogenes (Fig. 6f). Hence, these data suggest that c-Jun/JunB are important regulators for the functional properties of $\mathrm{cDC} 1$ in immune responses.

\section{C- Jun and JunB maintain CDC1 identity}

Next, we investigated whether the functional impairment of the remaining CD8 $\alpha$ splenic $\mathrm{cDC} 1$ was caused by an altered cDC1 lineage specification. Interestingly, the expression of
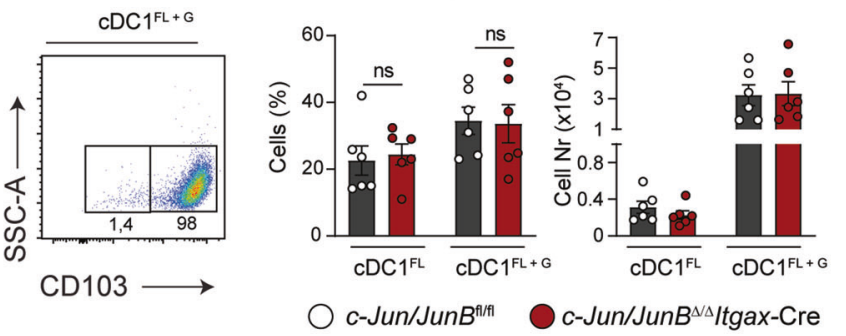

$\left(\mathrm{cDC}^{\mathrm{FL}}\right)$ or FLT3L + GM-CSF $\left(\mathrm{cDC}^{\mathrm{FL}}+\mathrm{G}\right)$ supplemented BM cell cultures of the indicated genotypes. Gating for $\mathrm{CD} 103^{-}$and $\mathrm{CD}_{103}{ }^{+} \mathrm{cDC} 1 \quad\left(\mathrm{CD} 24^{+} \mathrm{CD} 172 \mathrm{a}^{-}\right.$cDCs$)$and $\mathrm{cDC} 2{ }_{\left(\mathrm{CD} 24^{-}\right.}$ $\left.\mathrm{CD} 172 \mathrm{a}^{+} \mathrm{cDCs}\right)$ in vitro is shown. d Frequency and total numbers of in vitro generated $\mathrm{CD} 103^{-}$or $\mathrm{CD}_{103^{+}} \mathrm{CDC1}^{\mathrm{FL}}$ or $\mathrm{cDC} 1^{\mathrm{FL}+\mathrm{G}}$ described in (c) are shown. Data are representative of $2-3$ independent experiments. Dots indicate number of individual mice per experimental group. Error bars represent mean \pm SEM. Statistical significance was determined by unpaired two-tailed Student's $t$ test (b) and multiple $t$-test with the Holm-Šídák method (d). $* * P<0.01$, $* P<0.05$ and $\mathrm{ns}>0.05$.

TFs essential for cDC2 development and function, namely Irf4 and Klf4, were significantly increased in C-Jun/JunBdeficient $\mathrm{cDC} 1$, although expression levels were lower compared to cDC2 (Fig. 7a). Despite comparable levels of Batf3 and TFs involved in pDC development (Tcf4 and Spi$B)$, Irf8 was significantly reduced in $\mathrm{cDC1}$ lacking c-Jun/ JunB (Fig. 7a). Similarly, c-Jun/JunB-deficient $\mathrm{cDCl}^{\mathrm{FL}}$ showed upregulated Irf4 and Klf4 transcript levels, which remained high during the course of differentiation compared 
a c-Jun/JunB $B^{\text {f/fl }} \quad c-J u n / J u n B^{N \Delta} / \operatorname{tgax}-$ Cre

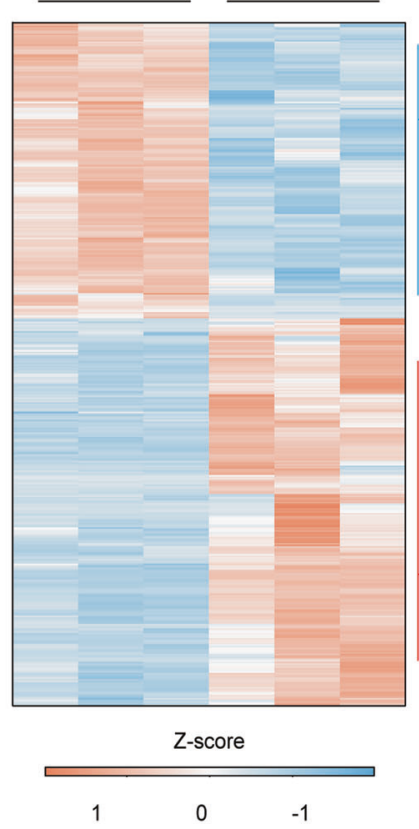

d
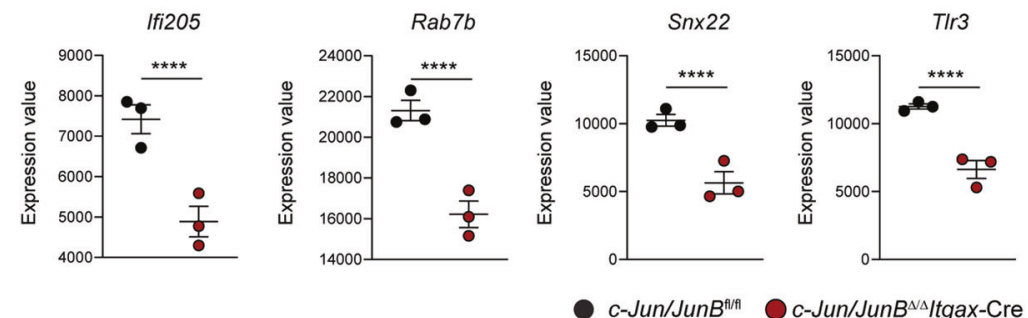

f
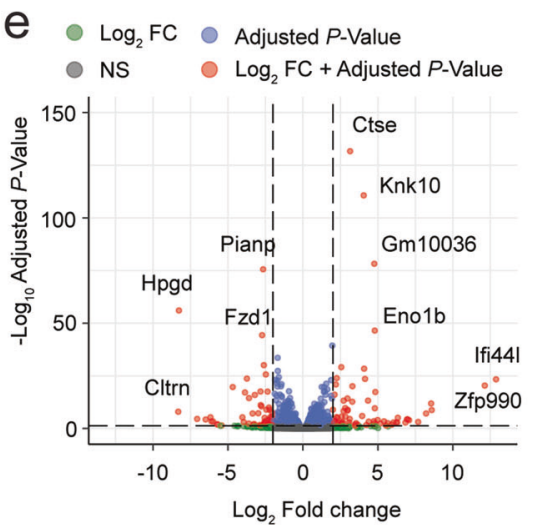

to control cells, while pDC- and cDC1-defining TFs were unchanged, except for Irf8 in pre-cDCs (Supplementary Fig. 6a-c). Consistently, splenic cDC1 lacking c-Jun/JunB showed significantly elevated IRF4 and reduced IRF8 protein levels (Fig. 7b-c). b

c-Jun/JunB ${ }^{\mathrm{fifl}} \quad \mathrm{c}-J u n / J u n B^{\Delta / \Delta} / \operatorname{tgax}-\mathrm{Cre}$

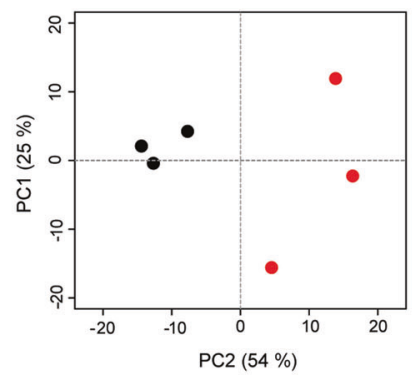

C

Enrichment plot :

GSE45365_CD8A_DC_VS_CD11B_DC_UP

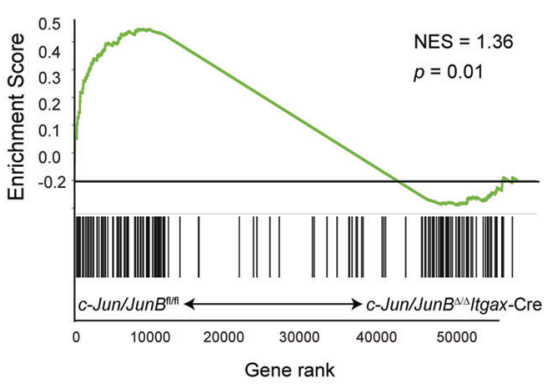


Fig. 5 Global transcriptional changes in c-Jun/JunB deficient cDC1. a RNA Seq was performed on FACS sorted $\mathrm{cDC}^{\mathrm{FL}}\left(\mathrm{CD} 24^{+}\right.$ $\left.\mathrm{CD} 11 \mathrm{c}^{+} \mathrm{B} 220^{-} \mathrm{CD} 115^{-} \mathrm{CD} 172 \mathrm{a}^{-}\right)$from indicated genotypes on day 8 of FTL3L supplemented BM cultures. Heat map shows differentially expressed genes (DEG) $\left(P<0.05, \log _{2} \mathrm{FC} \geq 1.0\right)$. Gene ontology (GO) analysis was performed on differentially expressed genes and selected, enriched GO terms are shown $(P<0.05)$. b Principal component analysis (PCA) of control and c-Jun/JunB deficient $\mathrm{CDC1} 1^{\mathrm{FL}}$ from RNA-Seq data generated as described in (a). c Gene set enrichment analysis (GSEA) for genes up-regulated in CD8 $\alpha^{+} \mathrm{DC}$ to $\mathrm{CD}_{11 b^{+}} \mathrm{DCs}$ (MSigDb v 6.2; Gene set: GSE45365_CD8A_DC_VS_CD11B_DC_UP) comparing control to c-Jun/JunB deficient $\mathrm{cDC} 1^{\mathrm{FL}}$. d Graphs show RNA expression of $\mathrm{cDC} 1$-specific transcripts in $c$-Jun/JunB $B^{\mathrm{f} / \mathrm{fl}}$ and $c$-Jun/JunB ${ }^{\Delta / \Delta}$ Itgax-Cre $\mathrm{cDC} 1^{\mathrm{FL}}$ RNA-Seq samples. e Volcano plot depicting DEG in c-Jun/JunB deficient $\mathrm{cDC}^{\mathrm{FL}}$ cells. f-g Venn diagrams show the overlap of deregulated genes in $c$-Jun/JunB deficient $c D C 1^{\mathrm{FL}}\left(\mathrm{abs}\left(\log _{2} \mathrm{FC} \geq 0.5\right)\right.$; c-Jun/JunB genes) to Batf3 ${ }^{-1-}$ splenic cDC1 (abs $\left(\log _{2} \mathrm{FC} \geq 1\right)$; Batf3 genes) [GSE40647] (f) or to $\operatorname{Irf4}{ }^{-I-} \operatorname{Irf} 8^{-/-} \mathrm{CDC1}^{\mathrm{FL}}$ expressing low versus high IRF8 ( $\operatorname{abs}\left(\log _{2} \mathrm{FC} \geq 1\right)$; IRF8 genes) [GSE140451] (g). Selected genes of interest which are deregulated in both experiments are listed on the side. Data are from an RNA-Seq experiment with $n=$ 3 per experimental group. Error bars represent mean \pm SEM. Statistical significance was determined by unpaired two-tailed Student's $t$ test (d). $* * * * P<0.0001, * P<0.05$.

UMAP analysis, revealed a reduction of $\mathrm{cDC} 1$ and a shift to a cDC2 phenotype in $c$-Jun/JunB ${ }^{\Delta / \Delta}$ Itgax-Cre mice (Fig. 7d). Analysis of the $\mathrm{cDC} 1$ population, defined in the UMAP space, showed an elevated expression of cDC2 specific markers (CD4 and CD11b) on c-Jun/JunB deficient $\mathrm{cDC} 1$ (Fig. 7e). Correct population clustering by UMAP and increased surface expression of CD4 and $\mathrm{CD} 11 \mathrm{~b}$ was confirmed by conventional gating (Supplementary Fig. 7b-d). Next, we sorted CD $8 \alpha$ rDC and CD103 $\mathrm{mDC}$ from sd-LN to better characterize the TF profile in these two population. Similar to splenic CD8 $\alpha$ cDC1 resident as well as migratory $\mathrm{cDC} 1$ showed a shift to a $\mathrm{CDC} 2$ phenotype with reduced Irf8, but increased Irf4 and Klf4 mRNA expression, whereas the pDC TFs Tcf4 and Spi-B were unchanged (Fig. 7f). Analysis of IRF4 and IRF8 protein by flow cytometry confirmed this altered CDC2-like phenotype (Fig. $7 \mathrm{~g}, \mathrm{~h}$ ). Lastly, deletion of c-Jun and JunB in sorted $\mathrm{cDC} 1$ and $\mathrm{CDC} 2$ was confirmed by quantitative RT-PCR (Supplementary Fig. 7e-f).

In conclusion, in this study we discovered a novel TF pair, c-Jun/JunB, required for CD8 $\alpha$ cDC1 development, function, and maintenance of their identity.

\section{Discussion}

cDC1 differentiation and identity is controlled by a complex network of linage-determining TFs. So far IRF8, ID2, NFIL3 and Batf3 have been reported as critical regulators at different stages of CD8 $\alpha$ and $\mathrm{CD} 103$ cDC1 development [7]. In this study, we identify the AP-1 family member's
c-Jun and JunB as two novel TFs essential for the development and function of the CD8 $\alpha \mathrm{cDC} 1$ lineage.

cDC1 develop from progenitor cells residing in the BM (CDPs), and differentiate in the tissue from a transitory, immediate progenitor population, the pre-cDC1 [7]. Our results demonstrate that the combined deletion of c-Jun and JunB in $\mathrm{CD}_{11 \mathrm{c}^{+}}$cells induces a severe defect in the specification of pre-cDCs to $\mathrm{CD} 8 \alpha$ cDC1. Importantly, other immune cell subsets developed normally in this mouse model, emphasizing c-Jun/JunB as specific-lineage determining TFs for $\mathrm{CD} 8 \alpha \mathrm{cDC} 1$ commitment.

In single c-Jun or JunB knock-out mice no effect on the CD8 $\alpha$ cDC1 pool was observed. Thus, c-Jun and JunB seem to either compensate for each other or cooperate by a currently unclear mechanism. Our data demonstrate for the first time such a non-redundant function for c-Jun and JunB in immune cells, but similar observations have been made in keratinocytes and hair follicle stem cells [25, 53].

Batf3 was the first AP-1 TF shown to be essential for $\mathrm{CD} 8 \alpha \mathrm{cDC} 1$ [13] and, depending on the mouse background, for CD103 cDC1 development [28, 42]. $129 \mathrm{SvEv}-$ Batf $^{-/-}$ mice lack $\mathrm{CD} 8 \alpha$ and $\mathrm{CD} 103 \mathrm{cDC} 1 \mathrm{~s}$ under homeostatic conditions [13, 42], whereas in a C57BL/6-background only a reduced splenic $\mathrm{CD} 8 \alpha \mathrm{cDC} 1$ population was observed [54, 55]. In our study both GEMM models, $c$-Jun/ $J u n B^{\Delta / \Delta} M x$-Cre and Itgax-Cre, are in a mixed (129Sv $\times$ C57BL/6) background and show only a reduction in lymphoid-resident $\mathrm{CD} 8 \alpha \mathrm{cDC} 1$. It thus remains to be investigated, whether the unaltered CD103 cDC1 pool is due to the mixed background.

Pathogenic infections or transplantations can restore the cDC1 pool independently of Batf3 [28, 56]. Batf3 can be replaced by its family members Batf or Batf 2 during infections with intracellular pathogens [28]. Batf has been described to hetero-dimerize with c-Jun, JunB or JunD in vitro, whereas for Batf2 and Batf3 only heterodimerization with c-Jun has been tested $[26,57,58]$. Our findings suggest that both c-Jun and JunB are nonredundant partners for Batf3 in the lineage decision of pre-cDCs. Additional studies are required to test, if c-Jun and JunB are also essential interaction partners for Batf or Batf2 to mediate compensatory DC development. In Batf $^{-1-}$ mice, also T-cell function is affected [59]. Therefore, c-Jun/JunB ${ }^{\Delta / \Delta}$ Itgax -Cre mice could be used as an alternative mouse model to study $\mathrm{CD} 8 \alpha \mathrm{cDC} 1$ biology under homeostatic and inflammatory conditions.

The classic DNA-binding element bound by AP-1 proteins is the TPA-responsive element (TRE) [16], but cooperation with IRF proteins expands the repertoire to AICE elements [28]. Although a proportion of the DEGs in c-Jun/JunB deficient cDC1 was overlapping with Batf3, the majority of genes were exclusive and associated with cell function, signaling and metabolism. 
a

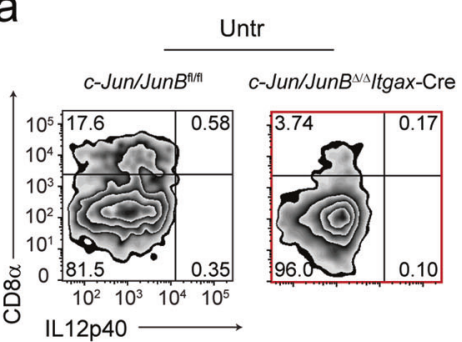

b CDC1 Function - IL-12

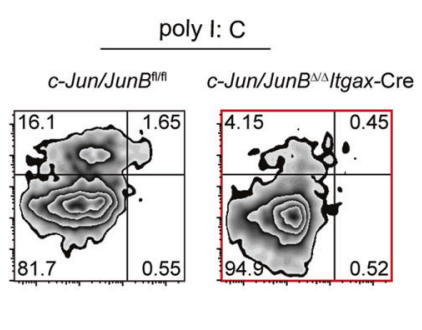

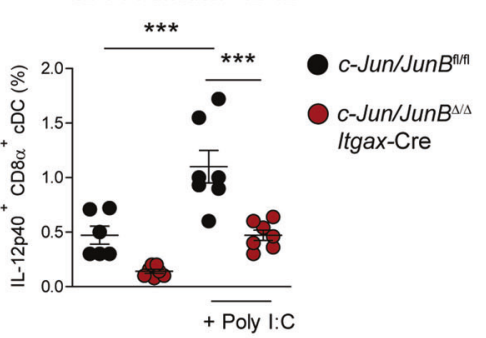

C

Splenic $\mathrm{CDC} 1$

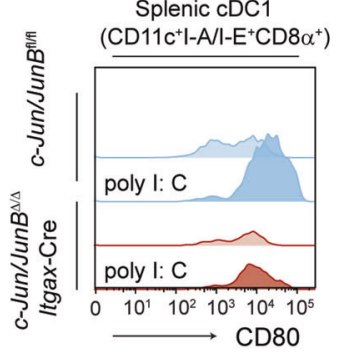

cDC1 Maturation - CD80

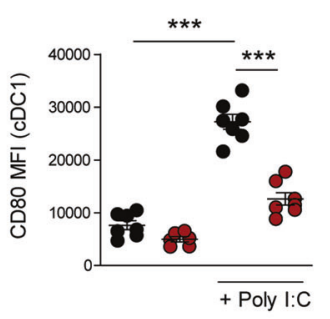

Splenic CDC1

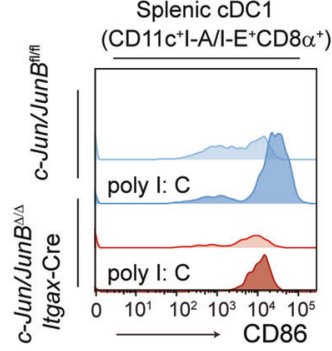

cDC1 Maturation - CD86

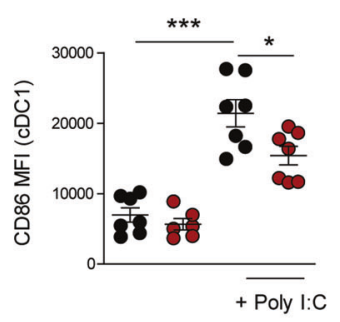

d

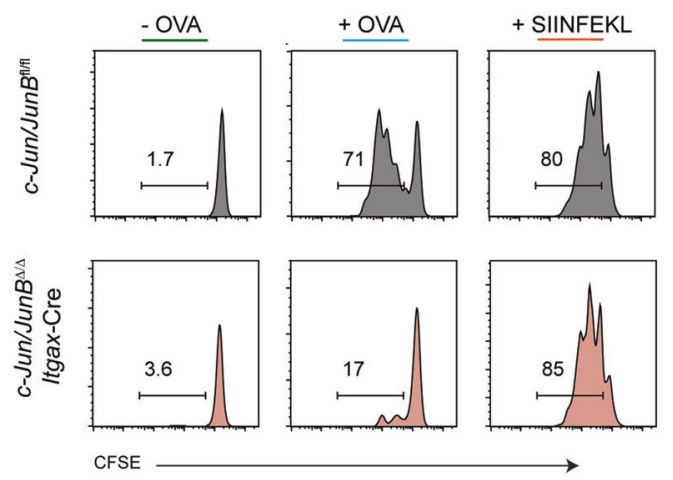

e

Antigen(cross)-presentation

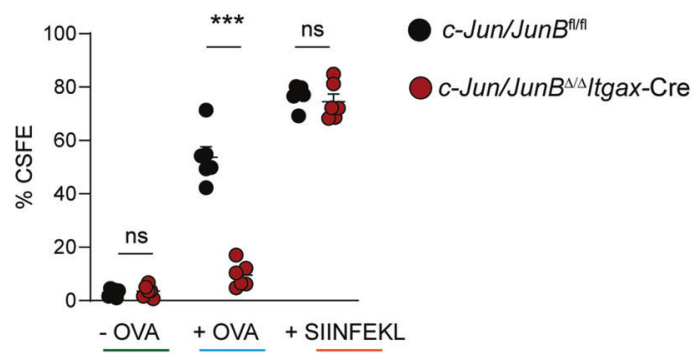

f

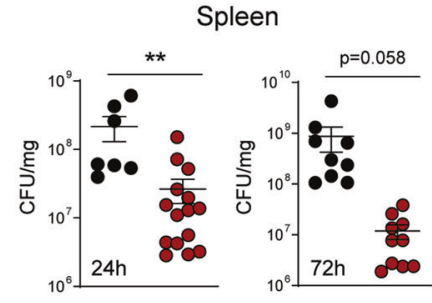

Liver

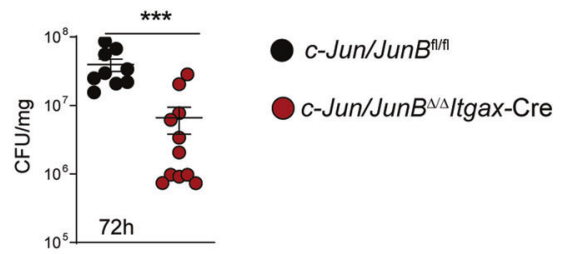

B220 ${ }^{+}$cells by MACS. $\mathrm{CDC}^{\mathrm{FL}}$ were then pulsed with Ovalbumin or SIINFEKL peptide and cultured with CFSE-labeled OT-I T cells at a ratio of 1:100 (DC: T cell ratio). After 3 days of co-culture, OT-I T cell proliferation (dilution of CFSE) was analyzed on live, single TCR$\beta^{+} \mathrm{CD} 8 \alpha^{+} \mathrm{T}$ cells by flow cytometry. Representative histograms are shown. e Graph shows proliferation of OT-I T cells, analyzed as described in (d) given as the percentage of CFSE dilution. f Listeria CFUs in spleen and liver of $c$-Jun/JunB ${ }^{\mathrm{f} / \mathrm{fl}}$ and $c$-Jun/JunB ${ }^{\Delta / \Delta}$ ItgaxCre mice infected i.v. with $L$. monocytogenes $\left(1 \times 10^{6}\right.$ per mouse $)$ at the indicated time points. Data are representative of two independent experiments. Dots indicate number of individual mice per experimental group. Error bars represent mean \pm SEM. Statistical significance was determined by unpaired two-tailed Student's $t$ test $(\mathbf{e}, \mathbf{f})$, or one-way ANOVA with Tukey post-test $(\mathbf{b}, \mathbf{c})$. ${ }^{* * *} P<0.001,{ }^{* *} P<$ $0.01, * P<0.05, \mathrm{~ns}>0.05$. 
a

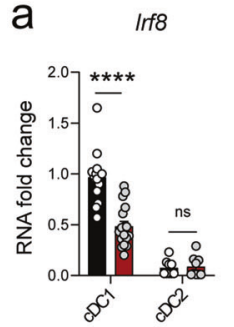

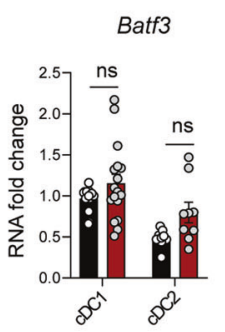

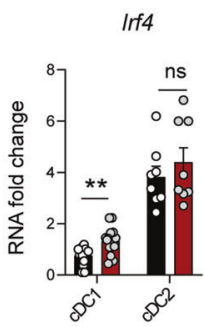

KIf4

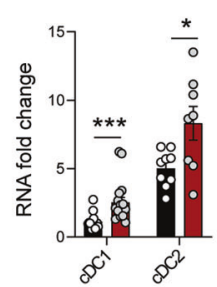

b

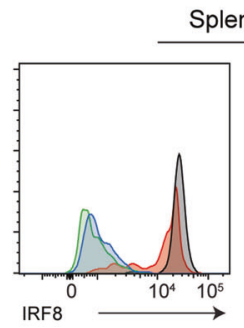

c-Jun/JunB $B^{\text {inf }}$

c-Jun/JunB ${ }^{\nu \Delta} / \operatorname{tgax}$-Cre

Tcf4

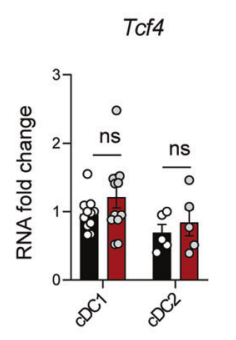

Spi-B

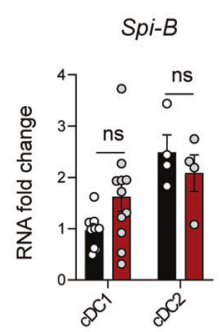

C

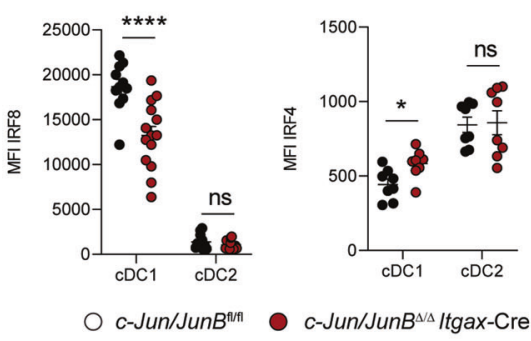

c-Jun/JunB

c-Jun/JunB $B^{\Delta /} /$ tgax-Cre

d
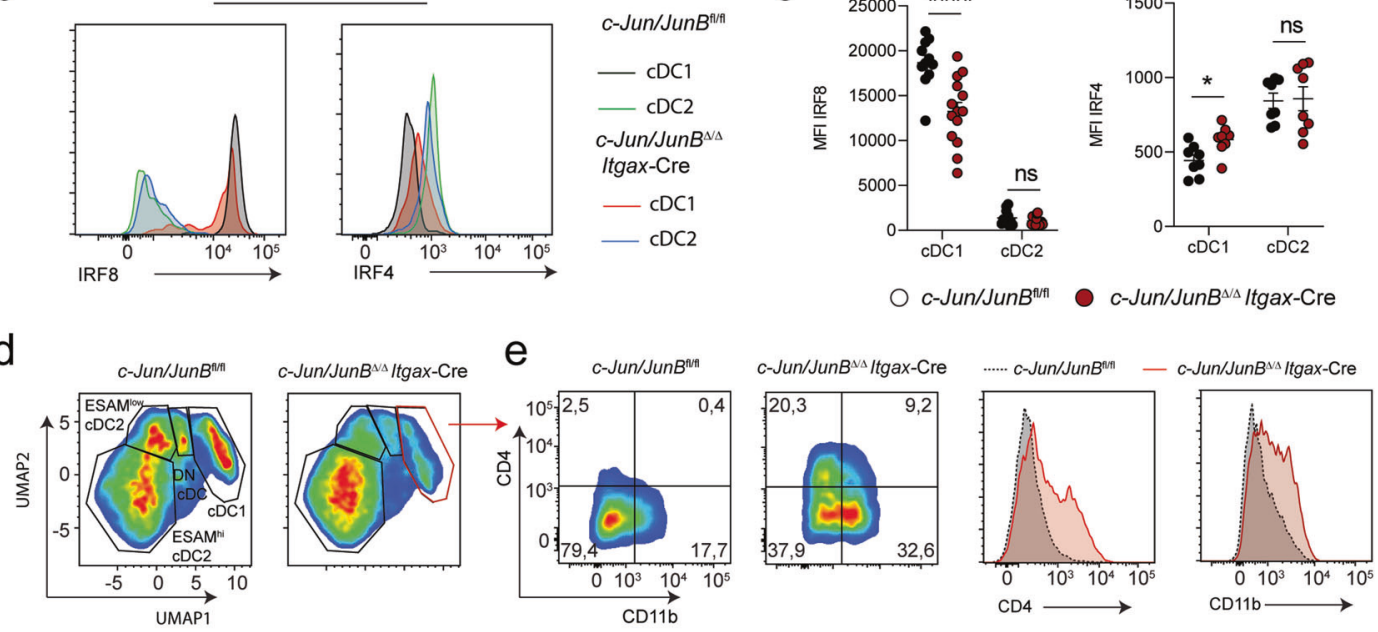

f
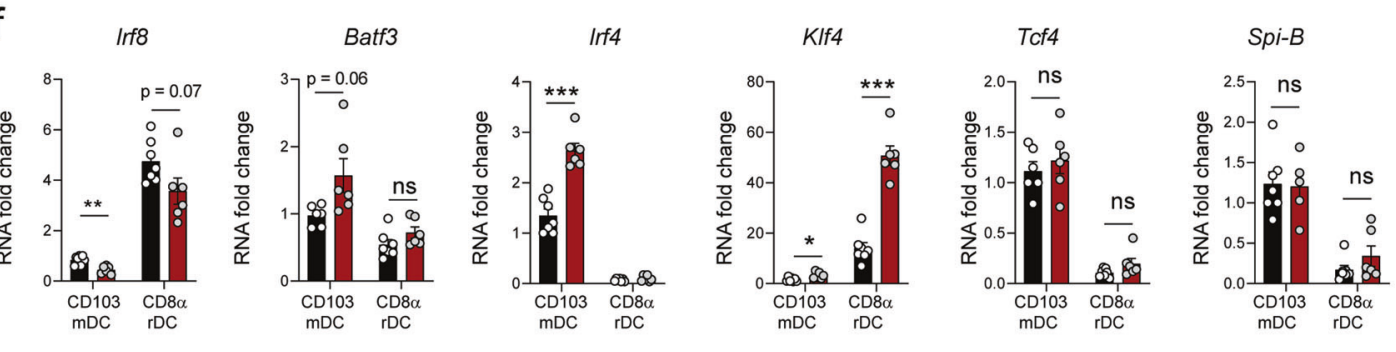

g

$\mathrm{h}$
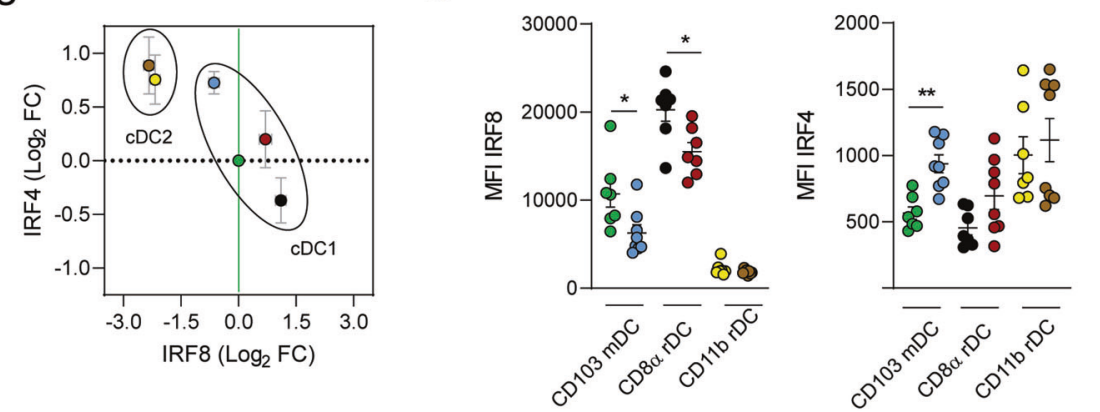

c-Jun/JunB $B^{\text {fl|fl }}$

- CD8 $\alpha$ rDC

- CD103 mDC

- CD11b rDC

c-Jun/JunB ${ }^{\Delta / \Delta} C D 110$-Cre

- $\mathrm{CD} 8 \alpha$ rDC

- CD103 mDC

- CD11b rDC

Future studies could elucidate the role of classical elements (TRE) bound by AP-1 dimers compared to AICE elements recognized by AP-1-IRF hetero-trimers for cDC1 biology.

Importantly, our findings emphasize that not only deletion of c-Jun/JunB in hematopoietic cells, but also in other cell types affects $\mathrm{cDC} 1$ development. In a recent study,
G-CSF, which is a direct transcriptional target of JunB in keratinocytes [44], has been shown to interrupt IRF8 dependent $\mathrm{CDC} 1$ development in the BM [45]. Here, we show that neutralization of G-CSF in $c-J u n / J u n B^{\Delta / \Delta} M x$-Cre mice partially rescued $\mathrm{CDC} 1$ numbers in the spleen. Future work should examine this novel extrinsic mechanism of cDC1 differentiation in more detail. 
Fig. 7 c-Jun and JunB maintain cDC1 identity. a Splenic CD8 $\alpha$ cDC1 (CD3 ${ }^{-}$CD19-BST-2 ${ }^{-}$Siglec- $\left.\mathrm{H}^{-} \mathrm{CD} 11 \mathrm{c}^{+} \mathrm{I}-\mathrm{A} / \mathrm{I}-\mathrm{E}^{+} \mathrm{XCR} 1^{+} \mathrm{CD} 8 \alpha^{+}\right)$

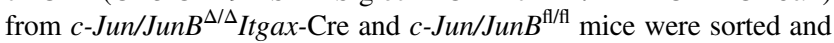
RT-qPCR analysis of Irf8, Batf3, Irf4, Klf4, Tcf4 and Spi-B mRNA was performed ( $n=11-17$ for $\mathrm{cDC} 1$ and $4-9$ for $\mathrm{cDC} 2$ subgroups). b Splenic cDC $\left(\mathrm{CD} 11 \mathrm{c}^{+} \mathrm{I}-\mathrm{A} / \mathrm{I}-\mathrm{E}^{+}\right)$subsets $\mathrm{cDC} 1\left(\mathrm{XCR} 1^{+} \mathrm{cDC}\right)$ and cDC2 $\left(\mathrm{CD} 172 \mathrm{a}^{+} \mathrm{CDC}\right)$ were analyzed for the protein expression of the transcription factors IRF4 and IRF8 by intracellular flow cytometry. Shown are representative histograms of IRF4 and IRF8 expression in $\mathrm{cDC} 1$ and $\mathrm{cDC} 2$ from indicated mice. c Graph depicts the mean fluorescence intensity (MFI) of IRF4 and IRF8 in splenic cDC subsets defined in (b). d UMAP analysis of splenic cDCs $\left(\mathrm{CD} 11 \mathrm{c}^{+} \mathrm{I}-\mathrm{A} / \mathrm{I}-\mathrm{E}^{+}\right)$ acquired by flow cytometry, including the surface markers CD4, $\mathrm{CD} 8 \alpha, \mathrm{CD} 11 \mathrm{~b}, \mathrm{CD} 172 \mathrm{a}, \mathrm{ESAM}$, and XCR1 in $c$-Jun/JunB ${ }^{\Delta / \Delta}$ ItgaxCre and $c$-Jun $/ J_{u n} B^{\mathrm{f} / \mathrm{fl}}$ mice. Samples were concatenated $(n=4$ per genotype) to perform the analysis. e Expression of CD4 and CD11b on cells within the cDC1 population, as defined by UMAP in (d), was analyzed. Flow cytometry plots (left) and histograms (right) are shown. f Lymph-node resident (CD3-CD19-NK1.1 TCR $\beta^{-} \mathrm{CD} 11 \mathrm{c}^{+} \mathrm{I}-\mathrm{A} /$ $\left.\mathrm{I}^{\mathrm{int}} \mathrm{XCR} 1^{+} \mathrm{CD} 8 \alpha^{+}\right)$and migratory $\mathrm{cDC} 1\left(\mathrm{CD} 3^{-} \mathrm{CD} 19^{-} \mathrm{NK} 1.1^{-} \mathrm{TCR} \beta^{-}\right.$ $\left.\mathrm{CD} 11 \mathrm{c}^{+} \mathrm{I}-\mathrm{A} / \mathrm{I}-\mathrm{E}^{\text {high }} \mathrm{XCR} 1^{+} \mathrm{CD} 103^{+}\right)$from $c$-Jun/JunB ${ }^{\Delta / \Delta}$ Itgax -Cre and $c$-Jun/JunB $B^{\mathrm{f} / / \mathrm{fl}}$ mice were sorted and RT-qPCR analysis of Irf8, Batf3, Irf4, Klf4, Tcf4 and Spi-B mRNA was performed $(n=6-7)$. $\mathbf{g}$ Lymphnode $\mathrm{CD} 8 \alpha \mathrm{rDC}\left(\mathrm{CD} 11 \mathrm{c}^{+} \mathrm{I}-\mathrm{A} / \mathrm{I}-\mathrm{E}^{\mathrm{int}} \mathrm{XCR}^{+} \mathrm{CD} 11 \mathrm{~b}^{-}\right), \mathrm{CD} 103 \mathrm{mDC}$ $\left(\mathrm{CD} 11 \mathrm{c}^{+} \mathrm{I}-\mathrm{A} / \mathrm{I}-\mathrm{E}^{\text {high }} \mathrm{XCR} 1^{+} \mathrm{CD} 11 \mathrm{~b}^{-} \mathrm{CD} 103^{+}\right)$and $\mathrm{CD} 11 \mathrm{~b}$ rDC $\left(\mathrm{CD} 11 \mathrm{c}^{+} \mathrm{I}-\mathrm{A} / \mathrm{I}-\mathrm{E}^{\mathrm{int}} \mathrm{XCR} 1^{-} \mathrm{CD} 11 \mathrm{~b}^{+}\right)$were analyzed by intracellular flow cytometry for IRF4 and IRF8 protein expression in indicated mice. Shown is the $\log _{2}$ Fold change of the MFI for IRF4 and IRF8 relative to the $c-J u n / J u n B^{\mathrm{f} / / \mathrm{ll}} \mathrm{CD} 103 \mathrm{mDC}$ subset, which is set to 0 .

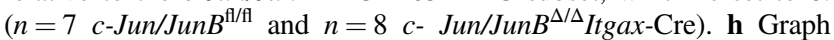
depicts the MFI of IRF4 and IRF8 in skin-draining lymph node cDC subsets as defined in (g). Data are representative of $2-4$ independent experiments. Dots indicate number of individual mice per experimental group. Error bars represent mean \pm SEM. Statistical significance was determined by multiple $t$-test with the Holm-Šídák method $(\mathbf{a}, \mathbf{c}, \mathbf{f}, \mathbf{h}) . * * * * P<0.0001,{ }^{*} * *<<0.001, * * P<0.01$, $* P<$ $0.05, \mathrm{~ns}>0.05$.

c-Jun/JunB deficient cDC1 have reduced Irf8 expression, despite normal levels of Batf3, and show a shift towards a cDC2 phenotype. Similarly, Batf $3^{-/-}$-deficient pre-CD8 DC cannot maintain IRF8 expression and divert to cDC2 [14].

Irf8 expression was also reduced in c-Jun/JunB deficient CD103 mDC, but their frequency was normal. Given the dependence of this DC subset on GM-CSF [47], further studies are needed to clarify its role in promoting CD103 $\mathrm{mDC}$ development/survival in the absence of c-Jun/JunB.

Collectively, our findings identify a key role for c-Jun/ JunB in $\mathrm{cDC} 1$ development, identity and function through extrinsic and intrinsic mechanisms.

\section{Data availability}

The RNA-Seq dataset has been deposited to GEO under the accession number GSE156484.

Acknowledgements We would like to thank the Core Facilities of the Medical University of Vienna, a member of VLSI, for cell sorting, preparation of sequencing libraries and RNA sequencing. We thank Life Science Editors for editorial assistance. We are grateful to Alexandra Bogusch and Temenuschka Baykuscheva-Gentscheva for technical assistance. We are grateful to Thomas Bauer for critical reading of the paper. We thank $M$. Hammer and the staff of the Department of Biomedical Research of the Medical University of Vienna for maintaining our mouse colonies.

Funding This work was supported by grants from the European Research Council (ERC) Advanced grant (ERC-2015-AdG TNT-Tumors 694883) and the Austrian Science Fund (FWF, PhD program W1212 "Inflammation and Immunity", and PhD program DOC 32-B28 "Tissue Home") to MS. MS's laboratory receives funding by the WWTF-project LS16-025 and the European Union's Horizon 2020 research and innovation program under the Marie Skłodowska-Curie grant agreement No. 766214 (Meta-Can). Funding to TD was provided by the Austrian Science Fund (FWF) through grants P 25186-B22 and SFB F6103. EFW is supported by the ERC (ERC-AdG 2016 CSI-Fun-741888), a H2020MSCA-ITN (ITN-2019-859860 - CANCERPREV) and the MUW.

Author contributions PN and BD contributed equally to this work. BD and PN performed and analyzed most of the experiments. MH participated in experimental design, interpretation of data, in the antigenpresentation experiment, cell sorting and writing of the paper. CDSF performed some of the cell culture in vitro experiments and assisted in flow cytometry experiments. RT performed the Listeria monocytogenes infections. SD performed analysis of data generated by RNA-Sequencing, TD and EFW provided technical support. MS supervised the project and provided the requested funding.

\section{Compliance with ethical standards}

Conflict of interest The authors declare no competing interests.

Ethical approval All animal experiments conducted were compliant with federal laws and guidelines of the Medical University of Vienna.

Publisher's note Springer Nature remains neutral with regard to jurisdictional claims in published maps and institutional affiliations.

Open Access This article is licensed under a Creative Commons Attribution 4.0 International License, which permits use, sharing, adaptation, distribution and reproduction in any medium or format, as long as you give appropriate credit to the original author(s) and the source, provide a link to the Creative Commons license, and indicate if changes were made. The images or other third party material in this article are included in the article's Creative Commons license, unless indicated otherwise in a credit line to the material. If material is not included in the article's Creative Commons license and your intended use is not permitted by statutory regulation or exceeds the permitted use, you will need to obtain permission directly from the copyright holder. To view a copy of this license, visit http://creativecommons. org/licenses/by/4.0/.

\section{References}

1. Clark GJ, Angel N, Kato M, López JA, MacDonald K, Vuckovic $\mathrm{S}$, et al. The role of dendritic cells in the innate immune system. Microbes Infect. 2000;2:257-72.

2. Onai N, Obata-Onai A, Schmid MA, Ohteki T, Jarrossay D, Manz MG. Identification of clonogenic common Flt3+M-CSFR+ plasmacytoid and conventional dendritic cell progenitors in mouse bone marrow. Nat Immunol. 2007;8:1207-16.

3. Guilliams M, Ginhoux F, Jakubzick C, Naik SH, Onai N, Schraml $\mathrm{BU}$, et al. Dendritic cells, monocytes and macrophages: a unified nomenclature based on ontogeny. Nat Rev Immunol. 2014;14:571-8. 
4. Merad M, Sathe P, Helft J, Miller J, Mortha A. The Dendritic Cell Lineage: Ontogeny and Function of Dendritic Cells and Their Subsets in the Steady State and the Inflamed Setting. Annu Rev Immunol. 2013;31:https://doi.org/10.1146/annurevimmunol-020711-74950.

5. Schlitzer A, Ginhoux F. Organization of the mouse and human DC network. Curr Opin Immunol. 2014;26:90-9.

6. Bachem A, Hartung E, Güttler S, Mora A, Zhou X, Hegemann A, et al. Expression of XCR1 Characterizes the Batf3-Dependent Lineage of Dendritic Cells Capable of Antigen CrossPresentation. Front Immunol. 2012;3.

7. Mildner A, Jung S. Development and Function of Dendritic Cell Subsets. Immunity. 2014;40:642-56.

8. Satpathy AT, Murphy KM, Kc W. Transcription factor networks in dendritic cell development. Semin Immunol. 2011; 23:388-97.

9. Belz GT, Nutt SL. Transcriptional programming of the dendritic cell network. Nat Rev Immunol. 2012;12:101-13.

10. Aliberti J, Schulz O, Pennington DJ, Tsujimura H. Reis e Sousa C, Ozato K, et al. Essential role for ICSBP in the in vivo development of murine CD8alpha + dendritic cells. Blood. 2003; 101:305-10.

11. Hacker C, Kirsch RD, Ju X-S, Hieronymus T, Gust TC, Kuhl C, et al. Transcriptional profiling identifies Id 2 function in dendritic cell development. Nat Immunol. 2003;4:380.

12. Kashiwada M, Pham NL, Pewe LL, Harty JT, Rothman PB. NFIL3/E4BP4 is a key transcription factor for CD8alpha(+) dendritic cell development. Blood. 2011;117:6193-7.

13. Hildner K, Edelson BT, Purtha WE, Diamond M, Matsushita H, Kohyama M, et al. Batf3 deficiency reveals a critical role for CD8alpha+ dendritic cells in cytotoxic T cell immunity. Science. 2008;322:1097-100.

14. Grajales-Reyes GE, Iwata A, Albring J, Wu X, Tussiwand R, Kc $\mathrm{W}$, et al. Batf3 maintains autoactivation of Irf8 for commitment of a CD8alpha(+) conventional DC clonogenic progenitor. Nat Immunol. 2015;16:708-17.

15. Wagner EF. Bone development and inflammatory disease is regulated by AP-1 (Fos/Jun). Ann Rheum Dis. 2010;69(Suppl 1): i86.

16. Eferl R, Wagner EF. AP-1: a double-edged sword in tumorigenesis. Nat Rev Cancer. 2003;3:859.

17. Novoszel P, Holcmann M, Stulnig G, De Sa Fernandes C, Zyulina $\mathrm{V}$, Borek I, et al. Psoriatic skin inflammation is promoted by cJun/AP-1-dependent CCL2 and IL-23 expression in dendritic cells. EMBO Mol Med. 2021:e12409.

18. Riera-Sans L, Behrens A. Regulation of alphabeta/gammadelta $\mathrm{T}$ cell development by the activator protein 1 transcription factor cJun. J Immunol (Baltim, Md: 1950). 2007;178:5690-700.

19. Carr TM, Wheaton JD, Houtz GM, Ciofani M. JunB promotes Th17 cell identity and restrains alternative CD4+ T-cell programs during inflammation. Nat Commun. 2017;8:301.

20. Passegué E, Wagner EF, Weissman IL. JunB Deficiency Leads to a Myeloproliferative Disorder Arising from Hematopoietic Stem Cells. Cell 2004;119:431-43.

21. Passegue E, Jochum W, Schorpp-Kistner M, Mohle-Steinlein U, Wagner EF. Chronic myeloid leukemia with increased granulocyte progenitors in mice lacking junB expression in the myeloid lineage. Cell 2001;104:21-32.

22. Bakiri L, Hamacher R, Graña O, Guío-Carrión A, Campos-Olivas $\mathrm{R}$, Martinez L, et al. Liver carcinogenesis by FOS-dependent inflammation and cholesterol dysregulation. J Exp Med. 2017;214:1387-409.

23. Szabowski A, Maas-Szabowski N, Andrecht S, Kolbus A, Schorpp-Kistner M, Fusenig NE, et al. c-Jun and JunB antagonistically control cytokine-regulated mesenchymal-epidermal interaction in skin. Cell. 2000;103:745-55.
24. Passegué E, Jochum W, Behrens A, Ricci R, Wagner EF. JunB can substitute for Jun in mouse development and cell proliferation. Nat Genet. 2002;30:158.

25. Zenz R, Eferl R, Kenner L, Florin L, Hummerich L, Mehic D, et al. Psoriasis-like skin disease and arthritis caused by inducible epidermal deletion of Jun proteins. Nature. 2005;437:369.

26. Iacobelli M, Wachsman W, McGuire KL. Repression of IL2 promoter activity by the novel basic leucine zipper p21SNFT protein. J Immunol (Baltim, Md: 1950). 2000;165: 860-8.

27. Echlin DR, Tae HJ, Mitin N, Taparowsky EJ. B-ATF functions as a negative regulator of AP-1 mediated transcription and blocks cellular transformation by Ras and Fos. Oncogene. 2000;19: 1752-63.

28. Tussiwand R, Lee WL, Murphy TL, Mashayekhi M, Kc W, Albring JC, et al. Compensatory dendritic cell development mediated by BATF-IRF interactions. Nature. 2012;490: 502-7.

29. Schraml BU, Hildner K, Ise W, Lee WL, Smith WA, Solomon B, et al. The AP-1 transcription factor Batf controls $\mathrm{T}(\mathrm{H}) 17$ differentiation. Nature. 2009;460:405-9.

30. Glasmacher E, Agrawal S, Chang AB, Murphy TL, Zeng W, Vander Lugt B, et al. A genomic regulatory element that directs assembly and function of immune-specific AP-1-IRF complexes. Science. 2012;338:975-80.

31. Behrens A, Sibilia M, David J-P, Möhle-Steinlein U, Tronche F, Schütz G, et al. Impaired postnatal hepatocyte proliferation and liver regeneration in mice lacking c-jun in the liver. EMBO J. 2002;21:1782-90.

32. Kenner L, Hoebertz A, Beil FT, Keon N, Karreth F, Eferl R, et al. Mice lacking JunB are osteopenic due to cell-autonomous osteoblast and osteoclast defects. J Cell Biol. 2004;164:613-23.

33. Caton ML, Smith-Raska MR, Reizis B. Notch-RBP-J signaling controls the homeostasis of CD8- dendritic cells in the spleen. $\mathrm{J}$ Exp Med. 2007;204:1653-64.

34. Kuhn R, Schwenk F, Aguet M, Rajewsky K. Inducible gene targeting in mice. Science. 1995;269:1427.

35. Drobits B, Holcmann M, Amberg N, Swiecki M, Grundtner R, Hammer $\mathrm{M}$, et al. Imiquimod clears tumors in mice independent of adaptive immunity by converting pDCs into tumor-killing effector cells. J Clin Investig. 2012;122:575-85.

36. Dobin A, Davis CA, Schlesinger F, Drenkow J, Zaleski C, Jha S, et al. STAR: ultrafast universal RNA-seq aligner. Bioinforma (Oxf, Engl). 2013;29:15-21.

37. Love MI, Huber W, Anders S. Moderated estimation of fold change and dispersion for RNA-seq data with DESeq2. Genome Biol. 2014;15:550.

38. Eden E, Navon R, Steinfeld I, Lipson D, Yakhini Z. GOrilla: a tool for discovery and visualization of enriched GO terms in ranked gene lists. BMC Bioinforma. 2009;10:48.

39. Subramanian A, Tamayo P, Mootha VK, Mukherjee S, Ebert BL, Gillette MA, et al. Gene set enrichment analysis: a knowledgebased approach for interpreting genome-wide expression profiles. Proc Natl Acad Sci USA. 2005;102:15545-50.

40. Liberzon A, Subramanian A, Pinchback R, Thorvaldsdottir H, Tamayo P, Mesirov JP. Molecular signatures database (MSigDB) 3.0. Bioinforma (Oxf, Engl). 2011;27:1739-40.

41. Vremec D, Shortman K. Dendritic cell subtypes in mouse lymphoid organs: cross-correlation of surface markers, changes with incubation, and differences among thymus, spleen, and lymph nodes. J Immunol (Baltim, Md: 1950). 1997;159: 565-73.

42. Edelson BT, Kc W, Juang R, Kohyama M, Benoit LA, Klekotka PA, et al. Peripheral CD103+ dendritic cells form a unified subset developmentally related to CD8alpha+ conventional dendritic cells. J Exp Med. 2010;207:823-36. 
43. Glitzner E, Korosec A, Brunner PM, Drobits B, Amberg N, Schonthaler HB, et al. Specific roles for dendritic cell subsets during initiation and progression of psoriasis. EMBO Mol Med. 2014;6:1312-27.

44. Meixner A, Zenz R, Schonthaler HB, Kenner L, Scheuch H, Penninger JM, et al. Epidermal JunB represses G-CSF transcription and affects haematopoiesis and bone formation. Nat Cell Biol. 2008;10:1003-11.

45. Meyer MA, Baer JM, Knolhoff BL, Nywening TM, Panni RZ, Su $\mathrm{X}$, et al. Breast and pancreatic cancer interrupt IRF8-dependent dendritic cell development to overcome immune surveillance. Nature. Communications. 2018;9:1250.

46. Guilliams M, Dutertre C-A, Scott Charlotte L, McGovern N, Sichien D, Chakarov S, et al. Unsupervised High-Dimensional Analysis Aligns Dendritic Cells across Tissues and Species. Immunity. 2016;45:669-84.

47. Greter M, Helft J, Chow A, Hashimoto D, Mortha A, AgudoCantero J, et al. GM-CSF Controls Nonlymphoid Tissue Dendritic Cell Homeostasis but Is Dispensable for the Differentiation of Inflammatory Dendritic Cells. Immunity. 2012;36:1031-46.

48. Mayer CT, Ghorbani P, Nandan A, Dudek M, Arnold-Schrauf C, Hesse $C$, et al. Selective and efficient generation of functional Batf3-dependent CD103+ dendritic cells from mouse bone marrow. Blood. 2014;124:3081-91.

49. Kim S, Bagadia P, Anderson DA III, Liu T-T, Huang X, Theisen DJ, et al. High Amount of Transcription Factor IRF8 Engages AP1-IRF Composite Elements in Enhancers to Direct Type 1 Conventional Dendritic Cell Identity. Immunity. 2020;53:759-74.e9.

50. Theisen DJ, Davidson JTT, Briseño CG, Gargaro M, Lauron EJ, Wang Q, et al. WDFY4 is required for cross-presentation in response to viral and tumor antigens. Science. 2018;362:694-9.
51. Miller JC, Brown BD, Shay T, Gautier EL, Jojic V, Cohain A, et al. Deciphering the transcriptional network of the dendritic cell lineage. Nat Immunol. 2012;13:888-99.

52. Edelson BT, Bradstreet TR, Hildner K, Carrero JA, Frederick KE, $\mathrm{Kc} \mathrm{W}$, et al. CD8alpha(+) dendritic cells are an obligate cellular entry point for productive infection by Listeria monocytogenes. Immunity. 2011;35:236-48.

53. Gago-Lopez N, Mellor LF, Megias D, Martin-Serrano G, Izeta A, Jimenez $\mathrm{F}$, et al. Role of bulge epidermal stem cells and TSLP signaling in psoriasis. EMBO Mol Med. 2019;11:e10697.

54. Edelson BT, Bradstreet TR, Kc W, Hildner K, Herzog JW, Sim J, et al. Batf3-dependent CD11b(low/-) peripheral dendritic cells are GM-CSF-independent and are not required for Th cell priming after subcutaneous immunization. PLoS ONE. 2011;6:e25660.

55. Jackson JT, Hu Y, Liu R, Masson F, D'Amico A, Carotta S, et al. Id2 expression delineates differential checkpoints in the genetic program of $\mathrm{CD} 8 \alpha+$ and $\mathrm{CD} 103+$ dendritic cell lineages. EMBO J. 2011;30:2690-704.

56. Seillet C, Jackson JT, Markey KA, Brady HJ, Hill GR, Macdonald $\mathrm{KP}$, et al. CD8alpha+ DCs can be induced in the absence of transcription factors Id2, Nfil3, and Batf3. Blood. 2013;121:1574-83.

57. Dorsey MJ, Tae HJ, Sollenberger KG, Mascarenhas NT, Johansen LM, Taparowsky EJ. B-ATF: a novel human bZIP protein that associates with members of the AP-1 transcription factor family. Oncogene. 1995;11:2255-65.

58. Aronheim A, Zandi E, Hennemann H, Elledge SJ, Karin M. Isolation of an AP-1 repressor by a novel method for detecting protein-protein interactions. Mol Cell Biol. 1997;17:3094-102.

59. Ataide MA, Komander K, Knöpper K, Peters AE, Wu H, Eickhoff $\mathrm{S}$, et al. BATF3 programs CD8 + T cell memory. Nat Immunol. 2020;21:1397-407. 